\title{
Diversidad, composición y estructura de la vegetación en un agropaisaje ganadero en Matiguás, Nicaragua
}

\author{
Dalia Sánchez Merlos ${ }^{1}$, Celia A. Harvey ${ }^{2}$, Alfredo Grijalva ${ }^{3}$, Arnulfo Medina ${ }^{1}$, Sergio Vílchez $^{1}$ \\ \& Blas Hernández ${ }^{1}$ \\ Fundación Cocibolca Apdo.-212. Managua, Nicaragua; dsanchez@catie.ac.cr \\ CATIE, Apdo. 7170, Turrialba, Costa Rica. \\ Herbario Nacional de Nicaragua, Universidad Centroamericana, Apdo. 69. \\ Recibido 11-III-2005. Corregido 17-VI-2005. Aceptado 01-VIII-2005.
}

\begin{abstract}
Vegetation diversity, composition and structure in a cattle agro-landscape of Matiguás, Nicaragua. The diversity, composition and structure of vegetation in a cattle landscape in Matiguás, Nicaragua was characterized, and the floristic and structural differences of six types of habitats (secondary forests, riparian forests, charrales, live fences and pastures with high and low tree cover) were compared. A total of 3949 trees of 180 species and 52 families were recorded. Forty six percent of the total trees reported for the landscape were represented by Guazuma ulmifolia (18.5\%), Bursera simaruba (13.2\%), Tabebuia rosea (6.3\%), Enterolobium cyclocarpum (4.2\%) and Albizia saman (3.4\%). Many of the dominant species in the landscape were typical of open and disturbed areas. There were significant differences between the different habitats in the patterns of tree species richness, abundance, diversity, structure and floristic composition. The riparian forests had greater tree richness $(\mathrm{p}=0.0001)$ and diversity $(\mathrm{p}=0.0009)$ than other habitats. The floristic composition varied across habitats, with pairs of habitats sharing between 18.4 and $51.6 \%$ of the same tree species, and with clear differences in composition between the forested (riparian and secondary forests) and agricultural habitats. Of the habitats studied, the riparian forests and secondary forests seem to have greatest value for the conservation of the flora in the agropaisaje because they have the greatest species richness, and maintain small populations of endangered species. On the basis of the study, we recommend including agricultural landscapes in strategies to conserve tree diversity and suggest measures to ensure the maintenance of tree diversity in the Matiguas landscape. Rev. Biol. Trop. 53(3-4): 387-414. Epub 2005 Oct 3.
\end{abstract}

Key words: Abundance, flora, fragmentation, habitats, pastures, silvopastoril systems.

La transformación y fragmentación de los bosques representan las principales causas de la pérdida de diversidad biológica a nivel global (Skole et al. 1993, Jang et al. 1996, citado por Gallego 2002, Meyers et al. 2000, Silva-Matos et al. 2005). En Nicaragua la vegetación ha sufrido una vasta deforestación producto de la colonización agrícola, el aprovechamiento de los bosques sin control, y la expansión de la ganadería extensiva (Stevens 2001). Se estima que el área deforestada en el país es de 13 millones de hectáreas (Pomareda 1999), con una tasa de deforestación anual de aproximadamente 75000 ha/año. Estos procesos provocan una serie de efectos negativos en la vegetación tales como la pérdida de especies y material genético, la invasión de especies generalistas y la interrupción en la polinización y dispersión de semillas (Kattan 2002).

Como consecuencia de la deforestación y fragmentación de los bosques, hoy en día muchas regiones de Nicaragua han sido transformadas a agropaisajes. Estos agropaisajes generalmente son dominados por una matriz de potreros o cultivos anuales, pero aún retienen alguna cobertura arbórea dispersa en forma de pequeños parches remanentes de bosques, franjas angostas de bosques ribereños ("riparios") y árboles dispersos. A veces estos paisajes también incluyen cercas vivas que han sido 
establecidas por los productores para dividir potreros o campos agrícolas y evitar el paso de animales (Harvey et al. 2004).

A pesar de que estos agropaisajes son comunes en Nicaragua (se estima que cubren alrededor del 31\% del territorio nacional; Pomareda 1999), existe muy poca información sobre la vegetación que mantienen y de las especies presentes. Tampoco existe información sobre las diferencias en la diversidad y composición de la vegetación presente en los diferentes tipos de cobertura arbórea presente.

Los objetivos principales de este estudio fueron: 1) caracterizar la diversidad, composición y estructura de la vegetación de un agropaisaje típico de la zona ganadera del país; y 2) comparar la diversidad, composición y estructura de la vegetación entre diferentes tipos de hábitats (bosques secundarios, bosques ribereños, charrales, cercas vivas, potreros con alta y baja cobertura arbórea).

Este estudio brinda información básica sobre la vegetación arbórea presente en el paisaje y permite evaluar la importancia de estos paisajes para la conservación. Además representa el primer estudio de vegetación arbórea en el paisaje ganadero del Municipio de Matiguás y el segundo estudio florístico de agropaisajes en Nicaragua (Sánchez et al. en prep.).

\section{MATERIALES Y MÉTODOS}

El estudio se realizó en la cuenca del rió Bulbul del municipio de Matiguás, departamento de Matagalpa, Nicaragua $\left(85^{\circ} 27^{\prime} \mathrm{N}, 12^{\circ} 50^{\prime}\right.$ O), con un área aproximada de $9200 \mathrm{~km}^{2}$. La zona de vida según la clasificación del mapa de ecosistema de Nicaragua es bosque semideciduo (Meyrat 2000).

El paisaje de Matiguás es un mosaico de potreros, fragmentos de bosques (6.8\%), charrales $(6.8 \%)$, bosques ribereños $(1.4 \%)$ y árboles dispersos. El paisaje esta dominado por pasturas que cubren aproximadamente $68.2 \%$ del paisaje (Kunth 2004, comunicación personal). La principal actividad es la ganadería de doble propósito (Ruiz et al. en prep.).
El estudio florístico se realizó de Junio 2003 a Julio 2004 en 6 tipos de hábitats: bosques secundarios (en adelante BS), bosques ribereños $(\mathrm{BR})$, charrales $(\mathrm{CH})$, cercas vivas (CV), potreros con alta cobertura arbórea (PAC, cobertura de 16-25\% definidos en base de la distribución de frecuencias de cobertura) $\mathrm{y}$ potreros con baja cobertura arbórea (PBC, cobertura de 1-5\%), seleccionando al azar un total de 8 unidades de muestreo para un total de 48 parcelas en base a la interpretación de una imagen Ikono (año 2002). En cada una de las unidades de muestreo seleccionadas, se utilizó una parcela de muestreo temporal. En los bosques secundarios, charrales, potreros con alta y baja cobertura se estableció una parcela de 0.1 ha $(20 \mathrm{~m}$ x $50 \mathrm{~m}$, Fig. 1a). En estas parcelas se identificaron y se midieron los árboles con diámetros mayores o iguales a $10 \mathrm{~cm}$ de dap, y se anotaron aspectos fenológicos como la presencia de flores, frutos y semillas. Las muestras colectadas fueron identificadas en el Herbario Nacional de Nicaragua.

Dentro de la parcela de 0.1 ha (con excepción de cercas vivas, que presentan un solo estrato) se establecieron 3 subparcelas de $5 \mathrm{x}$ $10 \mathrm{~m}$ (0.005 ha) en las cuales se identificaron los árboles con diámetros mayores o iguales a $10 \mathrm{~cm}$ de dap y arbustos leñosos con altura mayor a $1.5 \mathrm{~m}$. Estas subparcelas se ubicaron en dos esquinas opuestas de la parcela de 0.1 ha y una en el centro (Fig. 1a).

En los bosques ribereños se estableció un parcela de 100 × 10 m (0.1 ha) donde se midieron los árboles con diámetros mayores o iguales a $10 \mathrm{~cm}$ de dap y tres subparcelas de 5 x $10 \mathrm{~m}$ (0.005 ha, Fig. 1b) para medir los árboles menores o iguales a $10 \mathrm{~cm}$ de dap y arbustos. En cercas vivas se hizo un censo total de los árboles mayores o iguales a $10 \mathrm{~cm}$ de dap en $500 \mathrm{~m}$ lineales con un área efectiva de 0.1 ha $(500 \times 2$ m, Fig. 1c). En los hábitats de potreros con alta y baja cobertura se realizaron adicionalmente parcelas de $100 \mathrm{x}$ $100 \mathrm{~m}$ (1 ha) para medir los árboles mayores o iguales a $10 \mathrm{~cm}$ de dap y tener una mejor caracterización del sistema. 
a

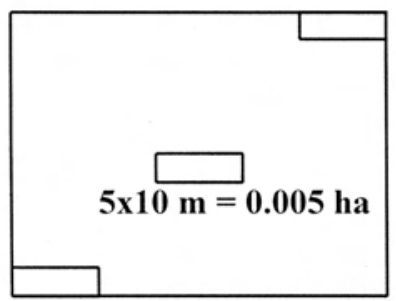

$20 \times 50 \mathrm{~m}=0.1$ ha b

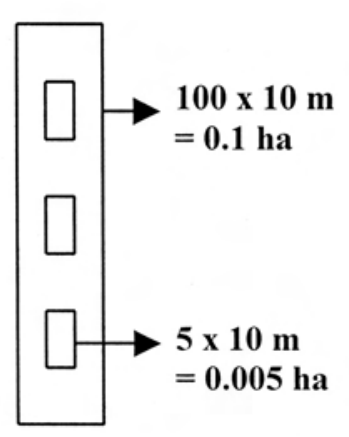

c

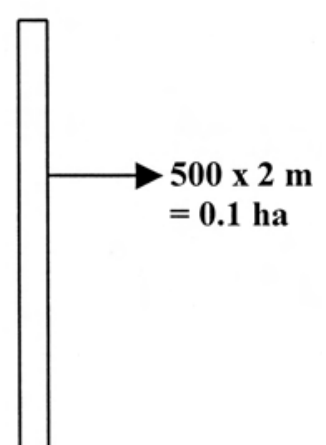

Fig. 1. Parcela de muestro de vegetación en: a) bosques secundarios, charrales, potreros con alta cobertura y potreros con baja cobertura (parcela de $20 \times 50 \mathrm{~m}$ y subparcelas de $5 \times 10 \mathrm{~m}$; b) bosques ribereños (parcela $100 \times 10 \mathrm{~m}$ y subparcelas de $5 \times 10 \mathrm{~m})$ y c) cercas vivas de $500 \mathrm{~m}$ lineales.

Fig. 1. Sample vegetation plot in: a) secondary forests, charrales and pasture with high and low tree cover (plot of $20 \times 50$ $\mathrm{m}$ and subplots of $5 \times 10 \mathrm{~m}$; b) riparian forests (plots of $100 \times 10 \mathrm{~m}$ and subplots of $5 \times 10 \mathrm{~m}$ ) and c) live fences of 500 linear meters.

Para caracterizar cada hábitat se seleccionaron 5 puntos aleatorios en cada parcela donde se midió la altura del dosel y se calculó un promedio.

Análisis de datos: Para cada una de las 48 parcelas se registró el número de especies y número de individuos de árboles. Se calculó por parcela el índice de diversidad de Shannon $^{1}$ (calcula la diversidad de especies) y Equitatividad $^{2}$ (indica en que medida las especies son abundantes por igual), utilizando el programa estadístico Infostat versión 1.6 (Robledo et al. 2000).

Se comparó el promedio de especies, promedio de individuos, promedios de índice de Shannon y Equitatividad entre hábitats utilizando análisis de varianza o Kruswall-Wallis. Se utilizó la prueba de Shapiro-Wilks para determinar la normalidad de los datos.

Se generó curvas de acumulación de especies para todos los hábitats (programa estadístico Ecosim versión 7.0, Gotelli et al. 2001) y cluster de similaridad utilizando el índice de Jaccard, con el programa estadístico Biodiversity Pro (McAleece et al. 1997). Además se utilizó el índice de Clench (especies acumuladas $=\mathrm{a} *$ abundancia $) /(1+(\mathrm{b} *$ abundancia $)$ para calcular la riqueza de especies esperadas para el paisaje utilizando el programa estadístico Infostat versión 1.6 (Robledo et al. 2000). Para caracterizar la estructura de la vegetación en cada parcela se calculó la distribución diamétrica, promedios de diámetros y altura, área basal y rangos de abundancias.

Resultados generales del paisaje: En total se registraron 3949 árboles, de 180 especies y 52 familias en 21.4 ha muestreadas. De estos individuos el 81\% (3 216 individuos) tuvieron diámetros mayores a $10 \mathrm{~cm}$ y $18 \%$ (733 individuos) menores a $10 \mathrm{~cm}$. El total de especies encontradas representan un $10 \%$ del total de especies arbóreas reportadas para el país (Salas 1993), y 37\% de las especies conocidas de los bosques del norte y litoral Atlántico de Nicaragua (Salas 1993, Pérez 2000, Vandermeer y Granzow 2000).

El índice de Clench estimó una riqueza total de 200 especies para el paisaje de Matiguás que representa $45 \%$ de las especies del pacifico y $30 \%$ de las especies del atlántico. Del total de especies reportadas para el paisaje el $46.8 \%$ pertenecen a cinco especies: Guazuma ulmifolia (733 individuos), Bursera simaruba (524 individuos), Tabebuia rosea (249 individuo), Enterolobium cyclocarpum (166 individuos) y Albizia saman (138 individuos). Muchas de 
estas especies son de usos múltiples y son retenidas por los productores de la zona porque sirven como madera, leña, forraje, postes etc.

De las 180 especies, 17 fueron comunes, con más de 50 individuos (Cuadro 1). Solamente 15 especies de 180 ocurrieron en todos los hábitats: Guazuma ulmifolia, Bursera simaruba, Tabebuia rosea, Enterolobium cyclocarpum, Albizia saman, Spondias mombin, Cordia alliodora, Genipa americana, Trichilia americana, Maclura tinctoria, Lysiloma auri- tum, Casearia corymbosa, Cecropia peltata, Lonchocarpus macrocarpus y Ceiba pentandra, las cuales representan $8.3 \%$ del total de especies registradas.

Las familias mayormente representadas en el paisaje según el número de especies fueron: Mimosaceae (16 spp., que representa el $15 \%$ de los individuos), Fabaceae (16 spp., $8 \%$ ), Caesalpiniaceae (9 spp., 2\%), Rubiaceae (9 spp., 4\%) Flacourtiaceae (9 spp., 2\%), y Moraceae (9 spp., 1\%).

CUADRO 1

Especies más comunes (en orden de abundancia) y su uso en el paisaje de Matiguás, Nicaragua

TABLE 1

Most common species (in order of abundance) and their land use in the Matiguás, Nicaragua

$\begin{array}{lcccccccccccc}\text { Especie } & \text { BS* } & \text { BR } & \text { CH } & \text { PAC } & \text { PBC } & \text { CV } & \text { Total** } & \% & & \text { USO } & \\ \text { Guazuma ulmifolia } & 137 & 54 & 87 & 385 & 61 & 49 & 773 & 19.57 & & \text { x } & \text { x } \\ \text { Bursera simaruba } & 55 & 16 & 30 & 15 & 8 & 400 & 524 & 13.26 & & \text { x } & \\ \text { Tabebuia rosea } & 15 & 1 & 9 & 101 & 24 & 99 & 249 & 6.30 & \text { x } & & \\ \text { Enterolobium cyclocarpum } & 16 & 10 & 14 & 91 & 26 & 9 & 166 & 4.20 & \text { x } & & \text { x } \\ \text { Albizia saman } & 4 & 4 & 10 & 75 & 39 & 6 & 138 & 3.49 & \text { x } & & \text { x } \\ \text { Pachira quinata } & 16 & 0 & 7 & 20 & 6 & 78 & 127 & 3.21 & \text { x } & & \\ \text { Spondias mombin } & 7 & 19 & 5 & 17 & 9 & 51 & 108 & 2.73 & \text { x } & & \\ \text { Inga vera } & 4 & 79 & 0 & 15 & 0 & 1 & 99 & 2.50 & & & \\ \text { Gliricidia sepium } & 4 & 0 & 9 & 9 & 6 & 55 & 83 & 2.10 & \text { x } & \text { x } & & \text { x } \\ \text { Cordia collococca } & 16 & 0 & 8 & 34 & 11 & 7 & 76 & 1.92 & & \text { x } & \\ \text { Acacia collinsii } & 19 & 12 & 18 & 15 & 5 & 0 & 69 & 1.74 & & \text { x } & \\ \text { Cordia alliodora } & 5 & 2 & 17 & 18 & 19 & 5 & 66 & 1.67 & \text { x } & & \\ \text { Genipa americana } & 15 & 14 & 10 & 17 & 3 & 7 & 66 & 1.67 & & \text { x } & \\ \text { Erythrina berteroana } & 1 & 1 & 0 & 2 & 0 & 57 & 61 & 1.54 & & & \text { x } \\ \text { Trichilia americana } & 11 & 9 & 8 & 7 & 7 & 17 & 59 & 1.49 & & \text { x } & \\ \text { Calycophyllum candidissimum } & 38 & 9 & 7 & 4 & 0 & 0 & 58 & 1.46 & \text { x } & \text { x } & \\ \text { Croton draco spp. panamensis } & 1 & 33 & 8 & 4 & 0 & 5 & 51 & 1.29 & & \text { x } & \end{array}$

Donde: BS*: bosque secundario, BR: bosque ribereño, $\mathrm{CH}$ : charral, PAC: potrero con alta cobertura arbórea, PBC: potrero con baja cobertura arbórea y CV: cerca viva.

** El total está basado en 3949 individuos registrados en 48 parcelas de 0.1 ha, 120 subparcelas de 0.005 ha y 16 parcelas de 1 ha.

Where: BS*: secondary forest, BR: riparian forest, $\mathrm{CH}$ : charral, PAC: high tree cover pasture, PBC: low tree cover pasture and $\mathrm{CV}$ : live fence.

** Total is based on 3949 individuals registered in 48 plots of 0.1 ha, 120 subplots of 0.005 ha and 16 plots of 1 ha. 
Dispersión: De las 180 especies reportadas en el paisaje, se encontró que 41 especies son dispersadas por aves, 18 especies por murciélagos, 16 especies por mamíferos, 10 especies por pequeños mamíferos, 3 especies por ganado y 92 especies por mecanismo de autodispersión (Grijalva 2004 comunicación personal, Janzen 1991, Apéndice 1 y 2).

Resultados generales en parcelas de 0.1 ha: En las parcelas de 0.1 ha se inventariaron 2470 individuos de árboles con dap $\geq$ $10 \mathrm{~cm}(62.5 \%$ de los árboles total) de un total de 134 especies de 41 familias arbóreas (Apéndice 1). El hábitat que presentó el mayor número de especies totales fue el bosque ribereño (80 spp.), seguido del bosque secundario (62 spp.). Los potreros tuvieron la riqueza de especies más baja (41 spp. en PAC y 23 spp. en PBC, Cuadro 2).

Del total de individuos Bursera simaruba fue la especie más numerosa con 496 individuos, seguido de Guazuma ulmifolia (489 individuos), Tabebuia rosea (147 individuos), Pachira quinata (109 individuos) y Spondias mombin (88 individuos).

Dominancia de especies: En cercas vivas, potreros, bosques secundarios y charrales la composición de especies está dominada por árboles de usos múltiples que tienen fácil propagación y beneficios como leña, forraje y madera (Cuadro 3). En cambio en los bosques ribereños la dominancia de especies fue más heterogénea, por la presencia de especies típicas de este tipo de ecosistema ej: Zigia longifolia.

Comparación de la diversidad de árboles con dap $\geq 10 \mathrm{~cm}$ en parcelas de 0.1 ha entre hábitats.
Hubieron diferencias estadísticas en el número de especies presentes en cada hábitat $\left(\mathrm{F}_{5,42}=9.32, \mathrm{p}=0.0001\right.$, Fig. 2a $)$. Los bosques ribereños tuvieron más especies de árboles que los demás hábitats, además los bosques secundarios registraron mayores especies que los dos tipos de potreros. Las abundancias de especies también mostraron diferencias entre hábitats $\left(\mathrm{F}_{5,42}=36.37, \mathrm{p}=0.0001\right.$, Fig. $\left.2 \mathrm{~b}\right)$. Un análisis de Kruskal Wallis indicó que las cercas vivas presentaron las mayores abundancias de árboles seguido por los bosques ribereños, bosques secundarios y potreros con alta cobertura. Los potreros con baja cobertura mostraron las abundancias más bajas.

Los índices de diversidad (Fig. 2c) también difirieron entre hábitats. El índice de Shannon indicó que el bosque ribereño fue más diverso que todos los demás hábitats $\left(\mathrm{F}_{5,42}=20.79, \mathrm{p}=0.0009\right)$. El índice de Equitatividad (Fig. 2d) mostró que los bosques ribereños y potreros con baja cobertura tuvieron una uniformidad mayor a los bosques secundarios, cercas vivas y potreros con alta cobertura $\left(\mathrm{F}_{5,42}=6.90, \mathrm{p}=0.0001\right)$.

Curva de acumulación de especies: Las curvas de acumulación de especies indican que los bosques ribereños son los hábitats que acumulan especies más rápidamente, seguido por los bosques secundarios y charrales (Fig. 3). Las curvas también indican que en todos los hábitats sería posible encontrar más especies con mayor esfuerzo de muestreo. El índice de Clench estimó una riqueza de 159 especies arbóreas en parcelas de 0.1 ha comparado con las 134 especies reportadas.

CUADRO 2

Riqueza y abundancia de árboles en parcelas de 0.1 ha

TABLE 2

Tree richness and abundance in plots of $0.1 \mathrm{ha}$

$\begin{array}{lccccccc}\text { Hábitat } & \text { BS } & \text { BR } & \text { CH } & \text { CV } & \text { PAC } & \text { PBC } & \text { Total } \\ \text { \# especies } & 62 & 80 & 50 & 52 & 41 & 23 & 134 \\ \text { \# individuos } & 397 & 425 & 298 & 946 & 320 & 84 & 2470\end{array}$


CUADRO 3

Las cinco especies de árboles más abundantes en cada hábitat y sus usos, en orden descendente de abundancia

TABLE 3

The five most abundant tree species in each habitat and their uses in descending order of abundance

\begin{tabular}{|c|c|c|c|c|c|}
\hline BS & BR & $\mathbf{C H}$ & $\mathrm{CV}$ & PAC & PBC \\
\hline $\begin{array}{c}\text { Guazuma } \\
\text { ulmifolia } \mathrm{L}, \mathrm{F}\end{array}$ & $\begin{array}{c}\text { Inga } \\
\text { vera } \mathrm{L}\end{array}$ & $\begin{array}{c}\text { Guazuma } \\
\text { ulmifolia L, F }\end{array}$ & $\begin{array}{c}\text { Bursera } \\
\text { simaruba } \mathrm{L}\end{array}$ & $\begin{array}{c}\text { Guazuma } \\
\text { ulmifolia L, F }\end{array}$ & $\begin{array}{c}\text { Guazuma } \\
\text { ulmifolia } \mathrm{L}, \mathrm{F}\end{array}$ \\
\hline $\begin{array}{c}\text { Bursera } \\
\text { simaruba } \mathrm{L}\end{array}$ & $\begin{array}{c}\text { Guazuma } \\
\text { ulmifolia L, F }\end{array}$ & $\begin{array}{c}\text { Bursera } \\
\text { simaruba } \mathrm{L}\end{array}$ & $\begin{array}{l}\text { Tabebuia } \\
\text { rosea } \mathrm{L}, \mathrm{F}\end{array}$ & $\begin{array}{l}\text { Tabebuia } \\
\text { rosea } \mathrm{L}, \mathrm{F}\end{array}$ & $\begin{array}{c}\text { Albizia } \\
\text { saman } \mathrm{M}, \mathrm{F}\end{array}$ \\
\hline $\begin{array}{c}\text { Calycophyllum } \\
\text { candidissimum } \\
\text { L, F, M }\end{array}$ & $\begin{array}{c}\text { Spondias } \\
\text { mombin } \\
\mathrm{L}, \mathrm{F}, \mathrm{M}\end{array}$ & $\begin{array}{c}\text { Cochlospermum } \\
\text { vitifolium } \\
\text { L }\end{array}$ & $\begin{array}{l}\text { Pachira } \\
\text { quinata } \\
\text { M }\end{array}$ & $\begin{array}{c}\text { Enterolobium } \\
\text { cyclocarpum } \\
\text { M, F }\end{array}$ & $\begin{array}{c}\text { Enterolobium } \\
\text { cyclocarpum } \\
\text { M, F }\end{array}$ \\
\hline $\begin{array}{c}\text { Enterolobium } \\
\text { cyclocarpum M, F }\end{array}$ & $\begin{array}{c}\text { Croton draco spp. } \\
\text { panamensis L }\end{array}$ & $\begin{array}{c}\text { Enterolobium } \\
\text { cyclocarpum M, F }\end{array}$ & $\begin{array}{c}\text { Erythrina } \\
\text { berteroana } \mathrm{F}\end{array}$ & $\begin{array}{c}\text { Albizia } \\
\text { saman } \mathrm{M}, \mathrm{F}\end{array}$ & $\begin{array}{c}\text { Cordia } \\
\text { alliodora } \mathrm{M}\end{array}$ \\
\hline $\begin{array}{l}\text { Pachira } \\
\text { quinata } \mathrm{M}\end{array}$ & $\begin{array}{c}\text { Zygia } \\
\text { longifolia } \mathrm{L}\end{array}$ & $\begin{array}{c}\text { Cordia } \\
\text { alliodora } \mathrm{M}\end{array}$ & $\begin{array}{l}\text { Gliricidia } \\
\text { sepium L, F }\end{array}$ & $\begin{array}{c}\text { Cordia } \\
\text { collococca L }\end{array}$ & $\begin{array}{c}\text { Bursera } \\
\text { simaruba } \mathrm{L}\end{array}$ \\
\hline
\end{tabular}

Donde: L: leña, M: madera y F: forraje.

Where: L: firewood, M: timber and F: forage.

a

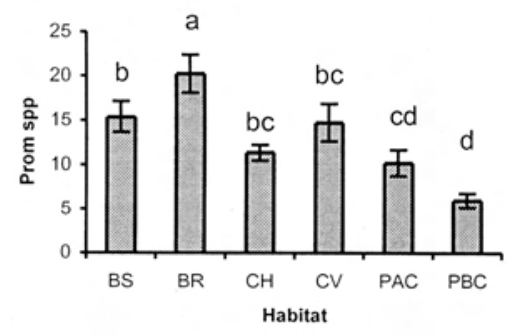

c

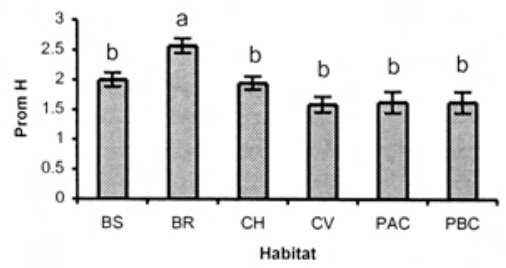

b

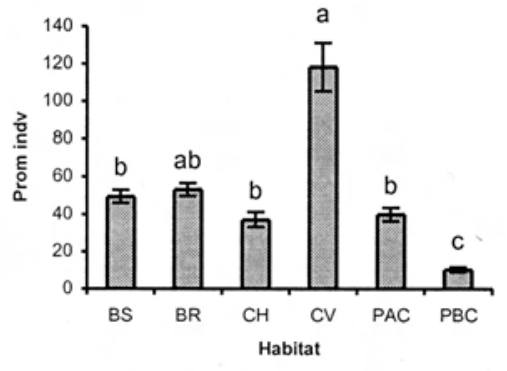

d

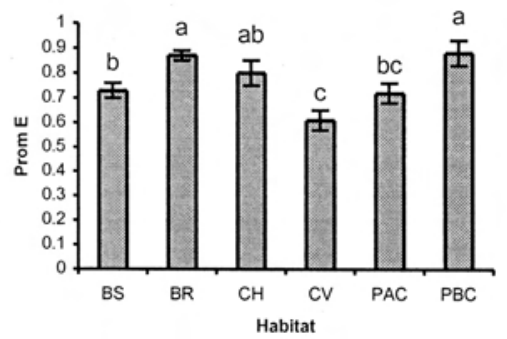

Fig. 2. Comparación de los promedios y errores estándares de a) riqueza, b) abundancia, c) diversidad y d) equitatividad de árboles en seis tipos de hábitats en Matiguás, Nicaragua. Los datos representan la información de parcelas de 0.1 ha de 8 parcelas por hábitat. Letras distintas en la misma fila indican diferencias significativas $(p<0.05)$.

Fig. 2. Comparison of means and standard errors of a) species richness, b) abundance, c) diversity and d) equitability of trees in six types of habitats in Matiguás, Nicaragua. Data represents information from 0.1 ha plots with a total of 8 plots per habitat. Different letters within the same row indicate significant differences $(\mathrm{p}<0.05)$. 
Índice de Jaccard: El índice de Jaccard mostró diferencias en la composición de especies entre hábitats. Los hábitats más similares fueron los charrales y los potreros con alta cobertura con un $51.6 \%$ de similaridad, y los charrales y cercas vivas con un $45.7 \%$. En cambio, los hábitats menos similares fueron los bosques ribereños y potreros que compartieron solamente el $18.3 \%$ y $21 \%$ de las mismas especies.

Según el análisis de cluster los hábitats se agrupan en 4 grupos: 1) charrales y potreros con alta cobertura; y potreros con baja cobertura; 2) cercas vivas; 3 ) bosques secundarios y 4) bosques ribereños (Fig. 4). La composición florística de hábitats manejados se separaron claramente de los hábitats bosques secundarios y bosques ribereños; esto se debe a que en potreros, cercas vivas y charrales el número de especies es más bajo.

Distribución de diámetros en los hábitats: El $86 \%$ de los individuos presentaron diámetros menores a $40 \mathrm{~cm}$, y el $14 \%$ de los individuos mostraron diámetros mayores a $40 \mathrm{~cm}$. El dap promedio de todos los árboles fue de $26.5 \mathrm{~cm}( \pm 1.08 \mathrm{EE}$, Fig. 5).

Las cercas vivas, bosques ribereños, bosques secundarios, charrales y potreros con alta

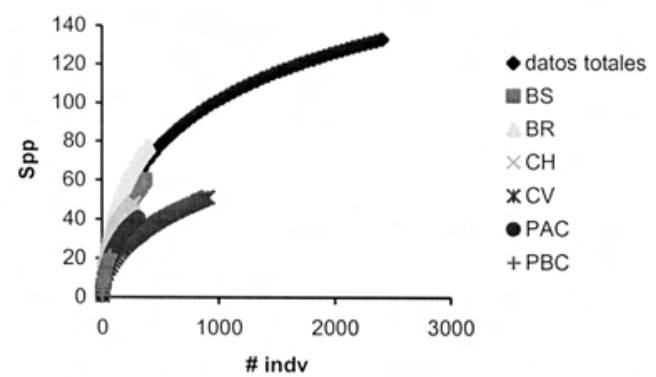

Fig. 3. Curva de acumulación de especies árboles (dap $\geq 10$ $\mathrm{cm}$ ) en bosque secundario (BS), bosque ribereño (BR), charral $(\mathrm{CH})$, cerca viva $(\mathrm{CV})$, potrero con alta cobertura arbórea (PAC), potrero con baja cobertura arbórea (PBC) y datos totales: número total de especies reportadas.

Fig. 3. Species accumulation curve for trees (dap $\geq 10 \mathrm{~cm}$ ) in secondary forest (BS), riparian forest (BR), charral (CH), live fence $(\mathrm{CV})$, high tree cover pasture (PAC), low tree cover pasture $(\mathrm{PBC})$ and total number of species recorded. cobertura presentaron una distribución diamétrica de una "J" invertida indicando una mayor abundancia de individuos en clases diamétricas inferiores. En cambio los potreros con baja cobertura presentaron una distribución más uniforme indicando poca regeneración (Fig. 6).

Los bosques ribereños tuvieron los árboles con mayor altura que el resto de hábitats $\left(\mathrm{F}_{5,42}=24.74, \mathrm{p}=0.0002\right.$; Cuadro 4). Los potreros con baja cobertura tuvieron mayores diámetros que los bosques secundarios, charrales y potreros con alta cobertura debido a que se encontraron varios individuos de Enterolobium cyclocarpum con clases diamétricas mayores a $40 \mathrm{~cm}$, lo que influyó en los análisis $\left(\mathrm{F}_{5,42}=25.98, \mathrm{p}=0.0385\right.$; Cuadro 4). Las cercas vivas presentaron el mayor valor de área basal probablemente a su alta densidad arbórea $\left(\mathrm{F}_{5,42}=29,11 \mathrm{p}=0.0001\right.$, Cuadro 4).

Resultados generales de los latizales en parcelas de 0.005 ha: Se registró un total de 733 individuos de dap $\leq 10 \mathrm{~cm}$ de 119 especies y 41 familias (en las parcelas de 0.005 ha, Apéndice 2). Se encontraron 33 especies arbustivas del sotobosque y estrato medio y 86 especies jóvenes del estrato arbóreo.

Las familias más representadas fueron Mimosáceas, Fabaceae, Flacourtiaceae,

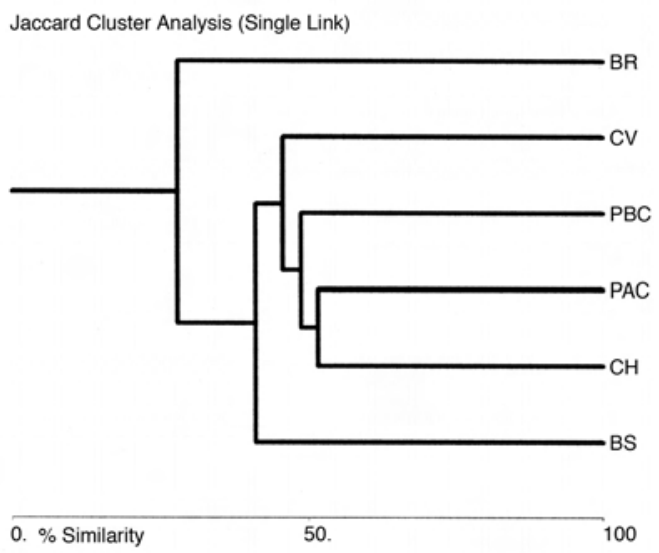

Fig. 4. Cluster de similaridad de hábitats en base a los índices de similaridad de Jaccard para árboles (dap $\geq 10 \mathrm{~cm})$.

Fig. 4. Cluster of habitat similarity based on Jaccard similarity indices for trees (dap $\geq 10 \mathrm{~cm})$. 


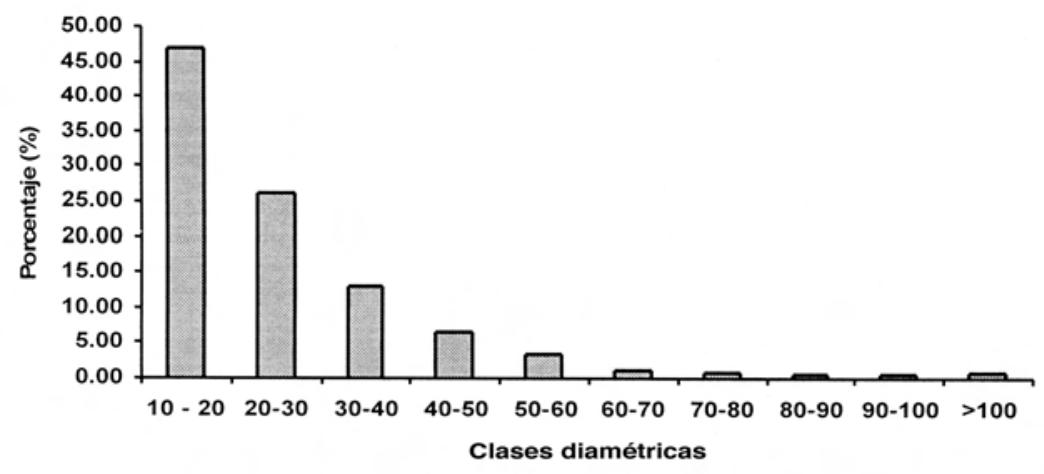

Fig. 5. Distribución diamétrica de árboles ( $\mathrm{n}=2470$ individuos) en 48 parcelas de 0.1 ha en Matiguás, Nicaragua.

Fig. 5. Tree diameter distribution ( $\mathrm{n}=2470$ individuals $)$ in 48 plots of 0.1 ha in Matiguás, Nicaragua.

\section{CUADRO 4}

Comparación de las alturas, diámetros promedios y área basal de los árboles en Matiguás, Nicaragua

TABLE 4

Comparison of tree heights, average diameters and basal areas in Matiguás, Nicaragua

$\begin{array}{lllll}\text { BS } & \text { BR } & \text { CH } & \text { CV } & \text { PAC }\end{array}$

$\begin{array}{lllllll}\begin{array}{l}\text { Altura promedio }(\mathrm{m}) \\ (\mathrm{n}=240 \text { individuos })\end{array} & 14.75 \pm 0.76 \mathrm{ab} & 17.29 \pm 0.36 \mathrm{a} & 11.78 \pm 1.04 \mathrm{bc} & 12.58 \pm 1.27 \mathrm{bc} & 11.03 \pm 1.55 \mathrm{c} & 9.53 \pm 1.33 \mathrm{c} \\ \begin{array}{l}\text { Diámetro promedio }(\mathrm{cm}) \\ (\mathrm{n}=2470 \text { individuos })\end{array} & 24.56 \pm 1.35 \mathrm{~b} & 27.84 \pm 1.29 \mathrm{ab} & 21.67 \pm 1.96 \mathrm{~b} & 26.33 \pm 1.8 \mathrm{ab} & 25.45 \pm 2.32 \mathrm{~b} & 33.39 \pm 4.44 \mathrm{a} \\ & & & & & \\ \begin{array}{l}\text { Área basal (m²/ha) } \\ (\mathrm{n}=2470 \text { individuos })\end{array} & 3.69 \pm 0.62 \mathrm{bc} & 4.72 \pm 0.58 \mathrm{ab} & 1.97 \pm 0.49 \mathrm{~cd} & 8.59 \pm 1,32 \mathrm{a} & 2.64 \pm 0.35 \mathrm{bcd} & 1.2 \pm 0,34 \mathrm{c}\end{array}$

Letras distintas en la misma fila indican diferencias significativas $(\mathrm{p}<0.05)$.

Different letters within the same row indicate significant differences $(p<0.05)$.

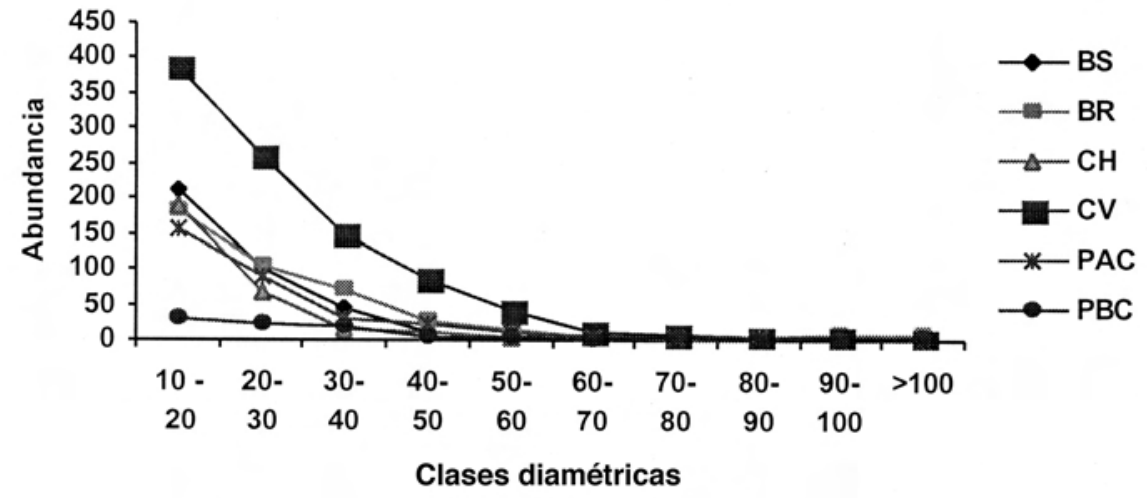

Fig. 6. Distribución de abundancias por clases diamétricas en seis hábitats (BS: bosque secundario, BR: bosque ribereño, $\mathrm{CH}$ : charral, CV: cerca viva, PAC: potrero con alta cobertura y PBC: potrero con baja cobertura arbórea) en Matiguás, Nicaragua.

Fig. 6. Abundance distribution per diameter classe in six habitats (BS: secondary forest, BR: riparian forest, CH: charral, CV: live fence, PAC: high tree cover pasture and PBC: low tree cover pasture) in Matiguás, Nicaragua. 
Rubiaceae y Caesalpiniaceae. Las especies de árboles que dominaron fueron Acacia collinsii (69 ind), Tabebuia rosea (49 ind), Calycophyllum candidissimum (31 ind) y Guazuma ulmifolia (31 indv). Los arbustos leñosos mayores a $1.5 \mathrm{~cm}$ de altura fueron dominados por Pehria compacta (16 ind). Hubo diferencias en la dominancia de especies arbóreas y arbustivas por hábitat (Cuadro 5).

Comparación de la diversidad de árboles $y$ arbustos con dap $\leq 10 \mathrm{~cm}$ en parcelas de 0.005 ha entre hábitat: Los bosques ribereños y bosques secundarios fueron los hábitats con mayor riqueza de especies de latizales (51 spp.), seguido por los charrales y potreros con alta cobertura (47 spp.). Las riquezas más bajas fueron encontradas en potreros con baja cobertura (30 spp., Cuadro 6).

Hubo diferencias en el promedio de especies de árboles con dap $\leq 10 \mathrm{~cm}$ entre hábitat
$\left(\mathrm{F}_{4,35}=5.87, \mathrm{p}=0.0010\right)$. Los bosques ribereños $\mathrm{y}$ charrales mostraron mayores números de especies que los potreros con alta y baja cobertura (Fig. 7a). Los bosques ribereños, bosques secundarios y potreros con alta cobertura tuvieron mayores promedios de abundancias (Fig. 7b) que los potreros con baja cobertura $\left(\mathrm{F}_{4,35}=9.94, \mathrm{p}=0.0398\right)$. El índice de Shannon (Fig. 7c) indicó que los bosques ribereños fueron más diversos que los potreros con baja cobertura arbórea $\left(\mathrm{F}_{4,35}=4.08 \mathrm{p}=0.0081\right)$. El índice de Equitatividad (Fig. 7d) no mostró diferencias estadísticas entre hábitat con una uniformidad para todos los hábitats mayor a 0.91 .

Comparación de árboles $\geq \mathbf{1 0} \mathrm{cm}$ de dap y árboles $\leq 10 \mathrm{~cm}$ de dap: Las curvas de acumulación de especies de árboles con dap $\leq 10$ cm mostraron el mismo patrón encontrado en las especies arbóreas adultas donde los bosques ribereños son los hábitats con mayor riqueza

CUADRO 5

Especies comunes de árboles $(\leq 10 \mathrm{~cm})$ y arbustos en parcelas de 0.005 ha en Matiguás, Nicaragua

TABLE 5

Common tree species ( $\leq 10 \mathrm{~cm}$ ) and shrubs in 0.005 ha plots in Matiguás, Nicaragua

\begin{tabular}{|c|c|c|c|c|c|}
\hline & BS & $\mathrm{BR}$ & $\mathrm{CH}$ & PAC & $\mathrm{PBC}$ \\
\hline \multirow[t]{3}{*}{ Árboles $\leq 10 \mathrm{~cm}$} & $\begin{array}{l}\text { Calycophyllum } \\
\text { candidissimun }\end{array}$ & $\begin{array}{l}\text { Inga } \\
\text { vera }\end{array}$ & $\begin{array}{l}\text { Acacia } \\
\text { collinsii }\end{array}$ & $\begin{array}{l}\text { Tabebuia } \\
\text { rosea }\end{array}$ & $\begin{array}{c}\text { Tabebuia } \\
\text { rosea }\end{array}$ \\
\hline & $\begin{array}{l}\text { Acacia } \\
\text { collinsii }\end{array}$ & $\begin{array}{l}\text { Ardisia } \\
\text { revoluta }\end{array}$ & $\begin{array}{c}\text { Cochlospermum } \\
\text { vitifolium }\end{array}$ & $\begin{array}{l}\text { Guazuma } \\
\text { ulmifolia }\end{array}$ & $\begin{array}{l}\text { Guazuma } \\
\text { ulmifolia }\end{array}$ \\
\hline & $\begin{array}{c}\text { Casearia } \\
\text { corymbosa }\end{array}$ & $\begin{array}{l}\text { Croton draco } \\
\text { spp. panamensis }\end{array}$ & $\begin{array}{c}\text { Bursera } \\
\text { simaruba }\end{array}$ & $\begin{array}{l}\text { Acacia } \\
\text { collinsii }\end{array}$ & $\begin{array}{l}\text { Albizia } \\
\text { saman }\end{array}$ \\
\hline Arbustos & $\begin{array}{c}\text { Pehria } \\
\text { compacta }\end{array}$ & $\begin{array}{l}\text { Garcia } \\
\text { nutans }\end{array}$ & $\begin{array}{c}\text { Pehria } \\
\text { compacta }\end{array}$ & $\begin{array}{l}\text { Baltimora } \\
\text { recta }\end{array}$ & $\begin{array}{l}\text { Senna } \\
\text { skinneri }\end{array}$ \\
\hline
\end{tabular}

CUADRO 6

Riqueza y abundancia de árboles y arbustos en parcelas de 0.005 ha en Matiguás, Nicaragua

TABLE 6

Tree and shrub richness and abundance in 0.005 ha in Matiguás, Nicaragua

\begin{tabular}{lcccccc}
\multicolumn{1}{c}{ Hábitat } & BS & BR & CH & PAC & PBC & Total \\
\# especies & 51 & 51 & 47 & 47 & 30 & 119 \\
\# individuos & 163 & 168 & 150 & 150 & 102 & 733
\end{tabular}


a

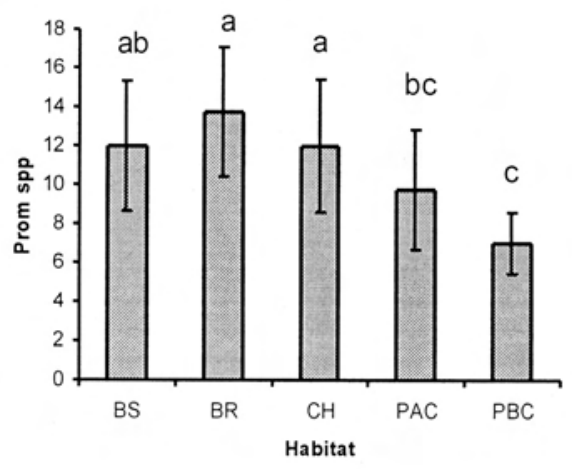

c

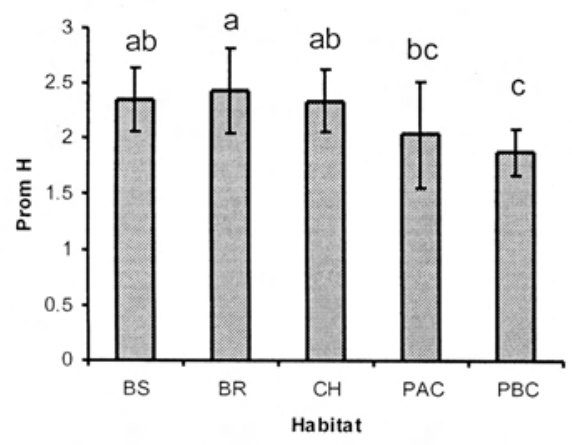

b

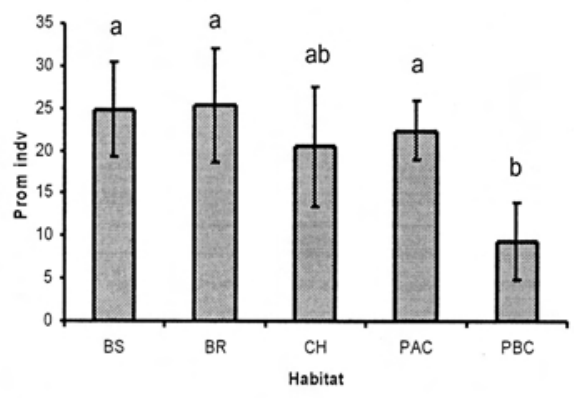

d

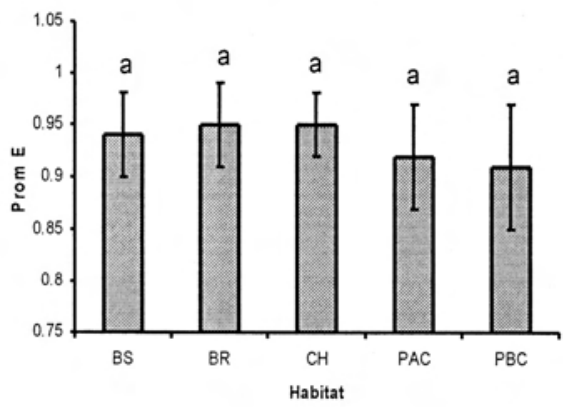

Fig. 7. Comparación de los promedios y errores estándares de a) riqueza, b) abundancia, c) diversidad y d) equitatividad de árboles con dap $\leq 10 \mathrm{~cm}$ de dap y arbustos en cinco tipos de hábitats en Matiguás, Nicaragua. Los datos representan la información total de 120 subparcelas de 0.005 ha. Letras distintas en la misma fila indican diferencias significativas (p < 0.05 ).

Fig. 7. Comparison of means and standard errors of a) species richness, b) abundance, c) diversity and d) equitability of trees $($ dap $\leq 10 \mathrm{~cm}$ ) and shrubs in five habitat types in Matiguás, Nicaragua. Data represents total information from 120 subplots of 0.005 ha. Different letters within the same row indicate significant differences $(\mathrm{p}<0.05)$.

de especies. De las 134 especies con dap $\geq 10$ $\mathrm{cm}$ se registraron 56 especies solamente en estado adulto, 75 especies en ambos estados, y 11 especies presentes solamente en estado de regeneración.

De las 20 especies más comunes con dap $\geq 10 \mathrm{~cm}$, se encontraron 12 especies que están representadas por una alta regeneración natural (Cuadro 7). Las especies comunes como adultos son también las comunes en latizales, y están representadas por especies de áreas abiertas (ej: T. rosea y G. americana), pioneras (ej: B. simaruba, C. vitifolium y C. draco spp. panamensis) y las que son retenidas por los productores por sus múltiples usos (ej: G. ulmifolia y C. alliodora).

\section{DISCUSIÓN}

Características generales de la vegetación: A pesar que el paisaje de Matiguás es altamente fragmentado y dominado por potreros (que ocupan el $68.2 \%$ del área), este aún mantiene una diversidad florística alta, con 180 especies arbóreas registradas en el paisaje y una riqueza estimada de 200 especies. La diversidad encontrada representa un $10 \%$ del total de 
CUADRO 7

Rangos de las especies comunes de regeneración y adultos encontradas en parcelas de Matiguás, Nicaragua

TABLE 7

Ranks of common regenerating and adult tree species found in plots Matiguás, Nicaragua

$$
\text { Especies } \geq 10 \mathrm{~cm} \text { dap } \quad \text { Rango } \quad \text { Especies } \leq 10 \mathrm{~cm} \text { dap }
$$

Albizia saman
Bursera simaruba
Calycophyllum candidissimum
Cochlospermum vitifolium
Cordia alliodora
Cordia collococca
Croton draco spp. panamensis
Enterolobium cyclocarpum
Erythrina berteroana
Erythrina fusca
Genipa americana
Gliricidia sepium
Guazuma ulmifolia
Inga vera
Pachira quinata
Spondias mombin
Tabebuia rosea
Trichilia americana

11

12

13

\author{
Acacia collinsii \\ Albizia saman \\ Ardisia revoluta \\ Bursera simaruba \\ Calycophyllum candidissimum \\ Casearia corymbosa \\ Cochlospermum vitifolium \\ Cordia alliodora \\ Croton draco spp. panamensis \\ Enterolobium cyclocarpum \\ Genipa americana \\ Guazuma ulmifolia \\ Inga vera \\ Lonchocarpus minimiflorus \\ Maclura tinctoria \\ Randia armata \\ Tabebuia rosea \\ Trichilia americana
}

Especies en negrilla fueron encontradas en ambos estados de desarrollo. Species in bold letters were found in both growth classes.

especies arbóreas reportadas para el país y $37 \%$ de las especies conocidas para el norte y litoral atlántico. No es posible saber que porcentaje retiene de la flora original dado que no existen datos florísticos sobre los bosques de la región, pero es probable que algunas especies han disminuido en abundancia o hayan sido eliminadas debido a la alta deforestación del paisaje y la actividad ganadera, como ha ocurrido en otros agropaisajes (Sánchez et al. en prep.).

Actualmente, la flora está dominada por especies generalistas de áreas abiertas o perturbadas como Guazuma ulmifolia, Bursera simaruba y Tabebuia rosea, entre otras. La dominancia de estas especies se debe en parte a su alta capacidad de regeneración en áreas degradadas (y en el caso de G. ulmifolia a su dispersión activa por el ganado; Esquivel et al. 2003), y en parte a la costumbre de los productores de dejar estas especies arbóreas en sus fincas para proveer productos y servicios (Martínez 2004). Por ejemplo, los productores dejan el G. ulmifolia porque sirve como fuente de leña para sus casas y como forraje para el ganado en la época seca, mientras que retienen a $T$. rosea para fines maderables y a B. simaruba para establecer cercas vivas. Las decisiones de los productores de cuales especies arbóreas dejar en sus charrales, potreros y cercas vivas parece haber tenido un importante impacto sobre la vegetación actual, ya que la mayoría de las especies comunes en el paisaje son las mismas que los productores seleccionan y retienen cuando establecen o manejan sus potreros (Martínez 2004).

Aunque el paisaje esta dominado por especies generalistas, aún mantiene valor para la 
conservación dado que presenta una mezcla interesante de especies arbóreas del Pacifico y Atlántico, retiene algunas especies típicas del bosque original y alberga algunas especies amenazadas. Por ser una región ubicada entre los dos vertientes, el paisaje de Matiguás presenta una flora de transición (Salas 1993), con especies como Astronium graveolens, Bravaisia integerrima, Calycophyllum candidissimum, Brosimum alicastrum, Manilkara chicle y especies de Ocotea. Actualmente, el paisaje retiene algunas especies típicas del bosque original (como Brosimum alicastrum, Cedrela odorata, Guarea grandifolia y Sideroxylon capiri), pero estas ocurren en bajas densidades y solamente representan el $16.1 \%$ de los árboles registrados en el paisaje considerados típicos de bosques intactos. Aún así, el paisaje logra mantener algunas especies arbóreas que han sido reportadas como amenazadas, dado sus bajas abundancias y poca regeneración natural (INIFOM 2001, MARENA 2003). Entre ellas están Astronium graveolens, Cedrela odorata, Manilkara chicle y Swietenia humilis.

La comunidad de árboles en el paisaje es joven, con la mayoría de árboles de diámetros y alturas pequeñas. Esta estructura probablemente se deba a la intervención a la que ha sido sometida el bosque y el paisaje en general. Todos los bosques en la zona han sido sometido a cosechas maderables, incendios u otras perturbaciones, y como consecuencia, los árboles grandes (especialmente aquellos de especies maderables) han desaparecido. Además, existe una presión constante sobre los árboles en el paisaje para madera y leña, y esta presión afecta a todos los hábitats estudiados.

Diferencias entre hábitats: Existen diferencias marcadas en la diversidad, riqueza, abundancia, y estructura de la vegetación entre los hábitats estudiados. Los bosques ribereños tuvieron mayor riqueza y diversidad de especies que los demás hábitats, probablemente por condiciones ecológicas favorables como humedad, bajas temperaturas y sombra que permiten una mayor diversidad de especies de coexistir (resultados similares fueron reportados por Pither et al. 2002 en bosques ribereños fragmentados en Belice y Sánchez et al. en prep. en un agropaisaje de bosque seco en Nicaragua). Las cercas vivas tuvieron las mayores densidades arbóreas y áreas básales, dado que los productores siembran los árboles a muy altas densidades y les dan poco manejo, dejando que los árboles alcancen el estado adulto (Harvey et al. 2003).

Además, se distinguió una clara diferencia en la composición arbórea entre los hábitats agropecuarios y por otro lado los bosques. Mediante un análisis de cluster utilizando el índice de similitud de Jaccard, se identificaron 4 grandes grupos de hábitats: 1) charrales y potreros con alta cobertura; y potreros con baja cobertura; 2) cercas vivas; 3) bosques secundarios y 4) bosques ribereños. Estas diferencias en la composición florística probablemente se deben a que los potreros, cercas vivas y charrales son más pobres en especies que los bosques riparios y bosques secundarios y son mayormente impactados por las actividades humanas como podas frecuentes, aplicación de herbicidas, chapias en potreros y pisoteo de ganado. Además, los potreros y cercas vivas están dominados por especies que son retenidas por los productores para múltiples usos como madera, leña y forraje (Ruiz et al. en prep.) o en el caso de cercas vivas, sembrados para formar la cerca, mientras que los bosques son dominados por especies que se regeneran naturalmente.

De los hábitats estudiados, los bosques ribereños y secundarios son claramente los hábitats con mayor valor para la conservación. Estos hábitats tienen una mayor riqueza y diversidad florística, mantienen mayor complejidad estructural que los demás hábitats, conservan más especies de interior de bosque, y aún retienen remanentes de especies maderables preciosas como Cedrela odorata, Manilkara chicle, y especies como Guarea grandifolia, y Astronium graveolens (aunque en bajas abundancias). Además, estos hábitats tienen las mayores densidades de árboles pequeños, indicando una buena regeneración. 
Los otros hábitats (charrales, cercas vivas y potreros con diferentes densidades arbóreas) son de menos valor para la conservación arbórea, pero aún retienen especies con valor maderable, frutal, y para leña, y son importantes fuentes de productos para los productores y merecen ser considerados en planes de manejo y conservación. Además, muchos de los árboles presentes en estos hábitats ofrecen alimento a una gran cantidad de especies de animales como los frutos de Byrsonima crassifolia, Carica papaya, Cordia dentata y Psidium guajava que son alimentos para aves, murciélagos y otros animales (Medina et al. 2004, Vilchez et al. 2004). Por lo tanto, estos hábitats podrían ser importantes en proveer recursos y hábitats para la vida silvestre dentro de las áreas pecuarias. Además, la presencia de los árboles en estos hábitats (y especialmente en las cercas vivas) puede ayudar a mantener la conectividad física del paisaje y servir como corredores o conectores a parches de bosques aislados probablemente ayudando a algunas especies de animales a movilizarse a través de la matriz agropecuaria (Harvey et al. 2003, Harvey y Haber 1999).

Implicaciones para el manejo y conservación de la biodiversidad: Nuestro estudio indica que el agropaisaje de Matiguás (y especialmente los bosques secundarios y bosques ribereños) aún mantiene una alta diversidad arbórea, incluyendo algunas especies consideradas amenazadas, y merece ser considerado en estrategias regionales enfocadas a la conservación de biodiversidad. Estudios similares de árboles en agropaisajes en Honduras también han llamado la atención al posible valor de los agropaisajes para conservar diversidad florística y la necesidad de empezar a manejar estos paisajes con una visión de conservación (Gordon et al. 2004, Gordon et al. 2003a y b).

Sin embargo, la diversidad arbórea en agropaisajes actualmente no esta bajo ningún tipo de protección y es amenazada por actividades agropecuarias. Por ejemplo, en Matiguás, la poca regeneración natural, la baja diversidad de especies regenerándose y la falta de regeneración de especies típicas de bosque sugiere que la riqueza de especies podría declinar a largo plazo, cuando los árboles adultos remanentes del bosque mueran o sean aprovechados.

Para evitar la pérdida de especies arbóreas en el paisaje y asegurar el mantenimiento de las especies amenazadas encontradas en el paisaje, se recomienda:

- conservar los parches actuales de bosques ribereños y bosques secundarios, y evitar la entrada de ganado para disminuir el efecto negativo del pisoteo sobre la regeneración natural,

- retener árboles adultos en el paisaje de especies amenazadas como Cedrela odorota, Swietenia humilis, Swietenia macrophylla, Astronimum graveolens, Sideroxylon capiri y Manilkara chicle que pueden servir como material genético y árboles semilleros en un futuro,

- diversificar la composición de las cercas vivas con más especies arbóreas y promover que las cercas se conecten con parches de bosques, charrales o bosques ribereños lo que probablemente puede hacer más hospitalaria la matriz agrícola para los animales (Harvey et al. 2003),

- mantener o aumentar árboles dispersos en potreros (especialmente especies nativas) para que sirvan como fuentes de semillas y además proporcionen hábitat y alimento a muchas especies de fauna y generen servicios a los productores como madera, leña y alimento para ganado, y

- manejar la regeneración natural como una estrategia para aumentar la cobertura arbórea en el agropaisaje seleccionando especies típicas de bosque en potreros para reemplazar a los árboles remanentes en el futuro.

\section{AGRADECIMIENTOS}

Agradecemos a los productores de Matiguás por permitirnos trabajar en sus fincas, 
y las contrapartes involucradas en el proyecto FRAGMENT (Universidad de Gottingen, Universidad de Bangor, UNA de Costa Rica, NITLAPAN y CATIE), y el Herbario Nacional de Nicaragua. El proyecto fue financiado por el Programa del Quinto Esquema de la Comunidad Europea INCO-DEV (Contract \# ICA4-CT-2001-10099).

\section{RESUMEN}

Se caracterizó la diversidad, composición y estructura de la vegetación en un paisaje ganadero en Matiguás, Nicaragua, y se comparó las diferencias florísticas y estructurales de seis tipos de hábitats (bosques secundarios, bosques ribereños, charrales, cercas vivas y potreros con alta y baja cobertura arbórea). Se registraron un total de 3949 árboles de 180 especies y 52 familias. El 46\% del total de especies informadas para el paisaje fueron representadas por Guazuma ulmifolia (18.5\%), Bursera simaruba (13.2\%), Tabebuia rosea (6.3\%), Enterolobium cyclocarpum (4.2\%) y Albizia saman (3.4\%). Muchas de las especies dominantes en el paisaje son típicas de áreas abiertas y perturbadas. Se encontraron diferencias significativas entre los diferentes hábitats en los patrones de riqueza, abundancia, diversidad, estructura y composición florística. Los bosques ribereños tuvieron mayor riqueza ( $\mathrm{p}=0.0001)$ y diversidad de especies $(\mathrm{p}=0.0009)$, que los demás hábitats. La composición florística vario entre hábitats, con pares de hábitats compartiendo solamente entre 18.4 y $51.6 \%$ de las mismas especies arbóreas, y con claras diferencias en composición entre los hábitats forestados (ribereños y bosques secundarios) y los hábitats agropecuarios. De los hábitats estudiados los bosques ribereños y bosques secundarios parecen ser los hábitats que tienen mayor valor para la conservación de la flora en el agropaisaje porque tienen la mayor riqueza de especies, además de que mantienen poblaciones bajas de especies maderables en peligro de extinción. En base a este estudio, recomendamos incluir los paisajes agrícolas en estrategias de conservación y sugerimos algunos criterios para asegurar el mantenimiento de la flora en el paisaje de Matiguás.

Palabras clave: Abundancia, flora, fragmentación, habitats, pasturas, sistema silvopastoril.

\section{REFERENCIAS}

Esquivel, H., M. Ibrahim, C.A Harvey, C. Villanueva, T. Benjamín \& F. Sinclair. 2004. Árboles dispersos en potreros de fincas ganaderas en un ecosistema seco de Costa Rica. RAFA. 10: 24-29.
Gallego, B. 2002. Estructura y composición de un paisaje fragmentado y su relación con especies arbóreas indicadoras en una zona de bosque muy húmedo tropical, de Costa Rica. Tesis de Maestría, CATIE, Turrialba, Costa Rica. 103 p.

Gordon J.E., D. Hawthorne, A. Garcia-Reyes, G. Sandoval \& A. Barrance. 2004. Assessing landscapes: a case study of tree and shrub diversity in the seasonally dry tropical forest of Oaxaca, México and Southern Honduras. Biol. Conserv. 117: 429-442.

Gordon J.E., D. Hawthorne, A. Garcia-Reyes, G. Sandoval \& A. Barrance. 2003a. Trees and farming in the dry zone of Southern Honduras II: the potential for tree diversity conservation. Agrof. Systems. 59: 107-117.

Gordon J.E., A. Barrance \& K. Schreckenberg. 2003b. Are rare species useful species? Obstacles to the conservation of tree diversity in the dry forest zone agroecosystems of Mesoamerica. Glob. Ecol. Biogeogr. 12: $13-19$.

Harvey, C.A., C. Villanueva, J. Villacís, M. Chacon, D. Muñoz, M. López, M. Ibrahim, R. Gómez, R. Taylor, J. Martínez, A. Navas, J. Sáenz, D. Sánchez, A. Medina, S. Vilchez, B. Hernández, A. Pérez, F. Ruiz, F. López, I. Lang, S. Kunth \& F. Sinclair. 2003. Contribución de las cercas vivas a la productividad e integridad ecológica de los paisajes agrícolas en América Central. RAFA. 10: 30-39.

Harvey, C.A., \& W.A. Haber. 1999. Remanent trees and the conservation of biodiversity in Costa Rican pastures. Agrof. Systems. 44: 37-68.

Janzen, D. 1991. Historia natural de Costa Rica. San José, Costa Rica. 822 p.

Kattan, G. 2002. Fragmentación: patrones y mecanismos de extinción de especies, p. 561-590. In M. Guariguata \& G. Kattan, (eds.). Ecología y conservación de bosques neotropicales. Cartago, Costa Rica, LUR.

Ministerio del Ambiente y Recursos Naturales (MARENA). 2003. Normas y procedimientos para la exportación e importación de especies de flora y fauna silvestre de Nicaragua. Managua, Nicaragua. 17 p.

Martínez, J. 2003. Conocimiento local de productores ganaderos sobre cobertura arbórea en la parte baja de la cuenca del río Bulbul en Matiguas, Nicaragua. Tesis de Maestría, CATIE, Turrialba, Costa Rica. 159 p.

Medina, A., C.A, Harvey, D. Sánchez, S. Vilchez \& B. Hernández. 2004. Diversidad y composición de chiropteros en un paisaje fragmentado de bosque seco en Rivas, Nicaragua. Managua, Nicaragua. Encuentros 68: 24-43. 
Meyrat, A. 2000. Los ecosistemas y formaciones vegetales de Nicaragua. Protierra / MARENA / CBA. Managua, Nicaragua. 30 p.

Myers, N., R.A. Mittermeier, C.G. Mittermeier, G.A. da Fonseca \& J. Kent. 2000. Biodiversity hotspots for conservation priorities. Nature 403: 853-858.

Pérez, M. 2000. Composición y diversidad de los bosques de la región Autónoma Atlántico Norte Nicaragüense: una base para el manejo sostenible. Tesis de Maestría, CATIE, Turrialba, Costa Rica. 155 p.

Pither, R., \& M. Kellman. 2002. Tree species in small tropical riparian forest fragments in Belize, Central America. Biodivers. Conserv. 11: 1623-1636.

Pomareda, C. 1999. Situación y perspectiva de la ganadería e industrias afines en Centroamérica. En: taller regional sobre desafíos y oportunidades de la ganadería e industrias afines en Centroamérica. Consejo agropecuario centroamericano / Proyecto RUTA-Banco Mundial. Guatemala, Guatemala. 12 p.

Robledo, C.W., J.A. Di Rienzo, W. Guzmán, M.G. Balzarini, F. Casanovas, L.A. González, \& E.M. Tablada. 2000. InfoStat/profesional versión 1.6. Departamento de estadística y biometría y de diseño de experimentos. Facultad de ciencias agropecuarias de la Universidad Nacional de Córdoba (FCA-UNC).

Salas, J. 1993. Árboles de Nicaragua. Servicio Forestal Nacional. HISPAMER. Managua, Nicaragua. 390 p.

Silva-Matos, D.M., G. D.F.M. Fonseca \& L. Silva-Lima. 2005. Differences on post-fire regeneration of the pioneer trees Cecropia glazioui and Trema micrantha in a lowland Brazilian Atlantic Forest. Rev. Biol. Trop. 53: 1-4.

Stevens, W. 2001. Introducción de vegetación, p. 1-23. In W. Stevens, C. Ulloa, A. Pool \& O. Montiel (eds.). Flora de Nicaragua. Jardín Botánico de Misurí.

Vilchez, S., C.A. Harvey, D. Sánchez, A. Medina \& B. Hernández. 2004. Diversidad de aves en un paisaje fragmentado de bosque seco en Rivas, Nicaragua. Managua, Nicaragua. Encuentros. 68: 60-75.

\section{REFERENCIAS DE INTERNET}

Gotelli, N.J. \& G.L. Entsminger. 2001. Ecosim: null models software for ecology. versión 7.0. Acquires Intelligence Inc. \& Kesey - Bear. (Consultada: Agosto 20, 2004, http://homepages. together.net/ $\sim$ gentsmin/ecosim.htm).

Instituto Nicaragüense de Fomento Municipal (INIFOM) 2001. Caracterizaciones municipales. PNUD. Managua, Nicaragua. (Consultada: Abril 12, 2004, www.inifom.gob.ni).

Mcaleece, N., J. Lambshead, G. Patterson \& J. Gage. 1997. BioDiversity Professional. The natural history museum and the scottish association for marine science. (Consultada: Agosto 26, 2004, http://www. sams.ac.uk/dml/projects/bentic/bdpr/index.htm).

Vandermeer, J., \& I. Granzow. 2000. Estudio de la dinámica de sucesión tras abandono de agricultura en la Región Autónoma Atlántico Sur. (Consultada: Octubre 10, 2004, www.biology.lsa.umich.edu/ research/hurricane/post-ag.html). 


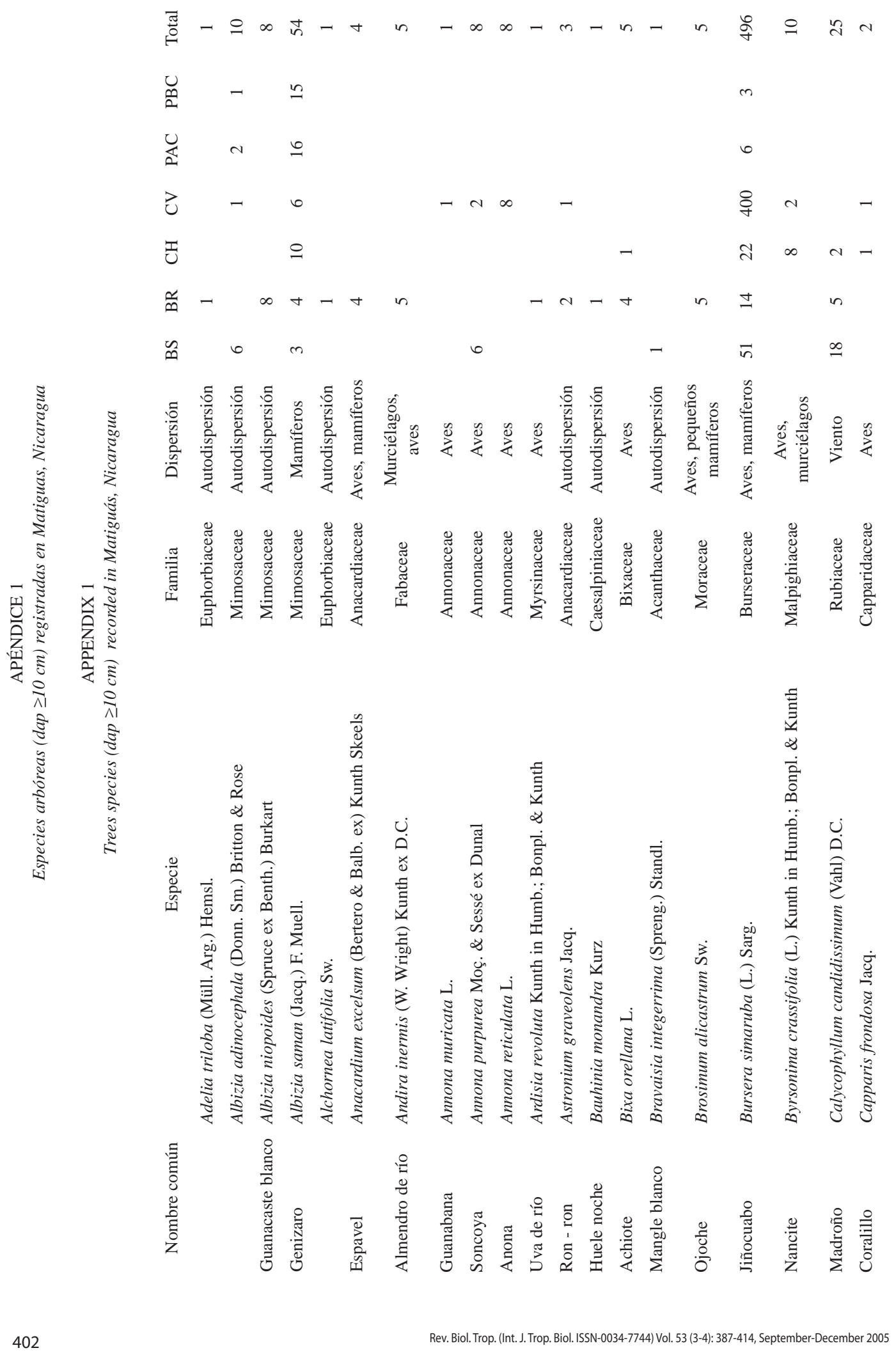




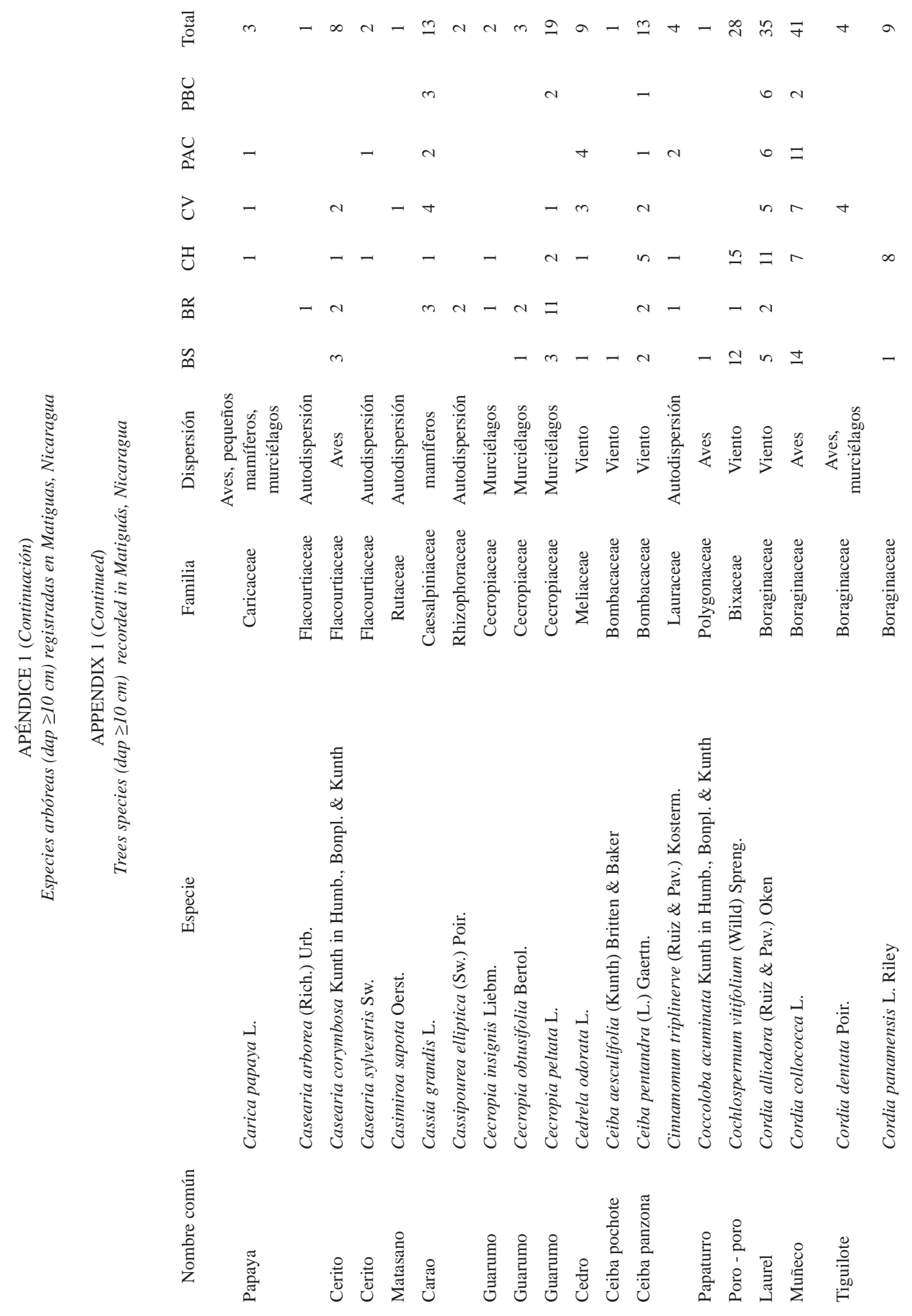

Rev. Biol. Trop. (Int. J. Trop. Biol. ISSN-0034-7744) Vol. 53 (3-4): 387-414, September-December 2005 


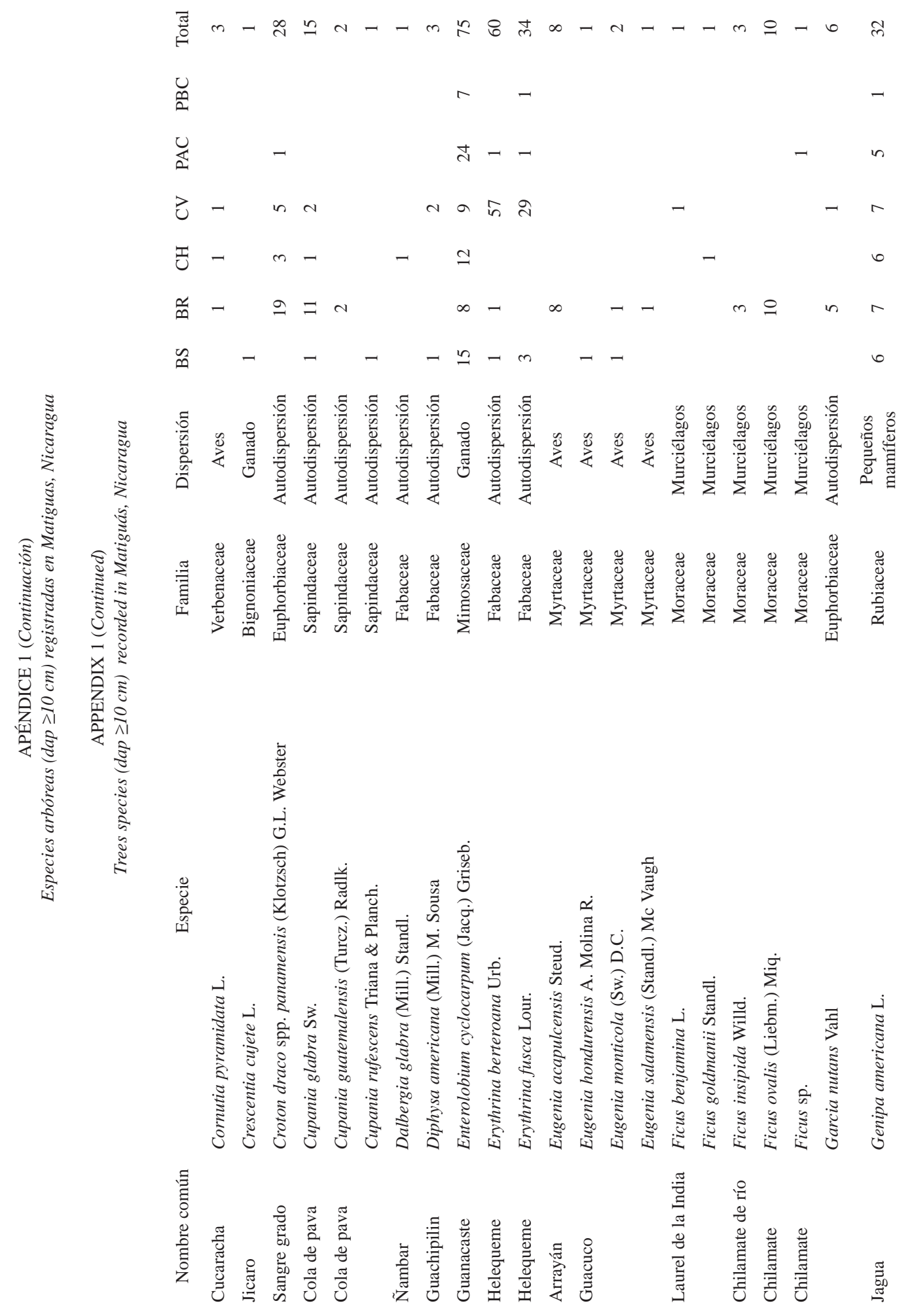




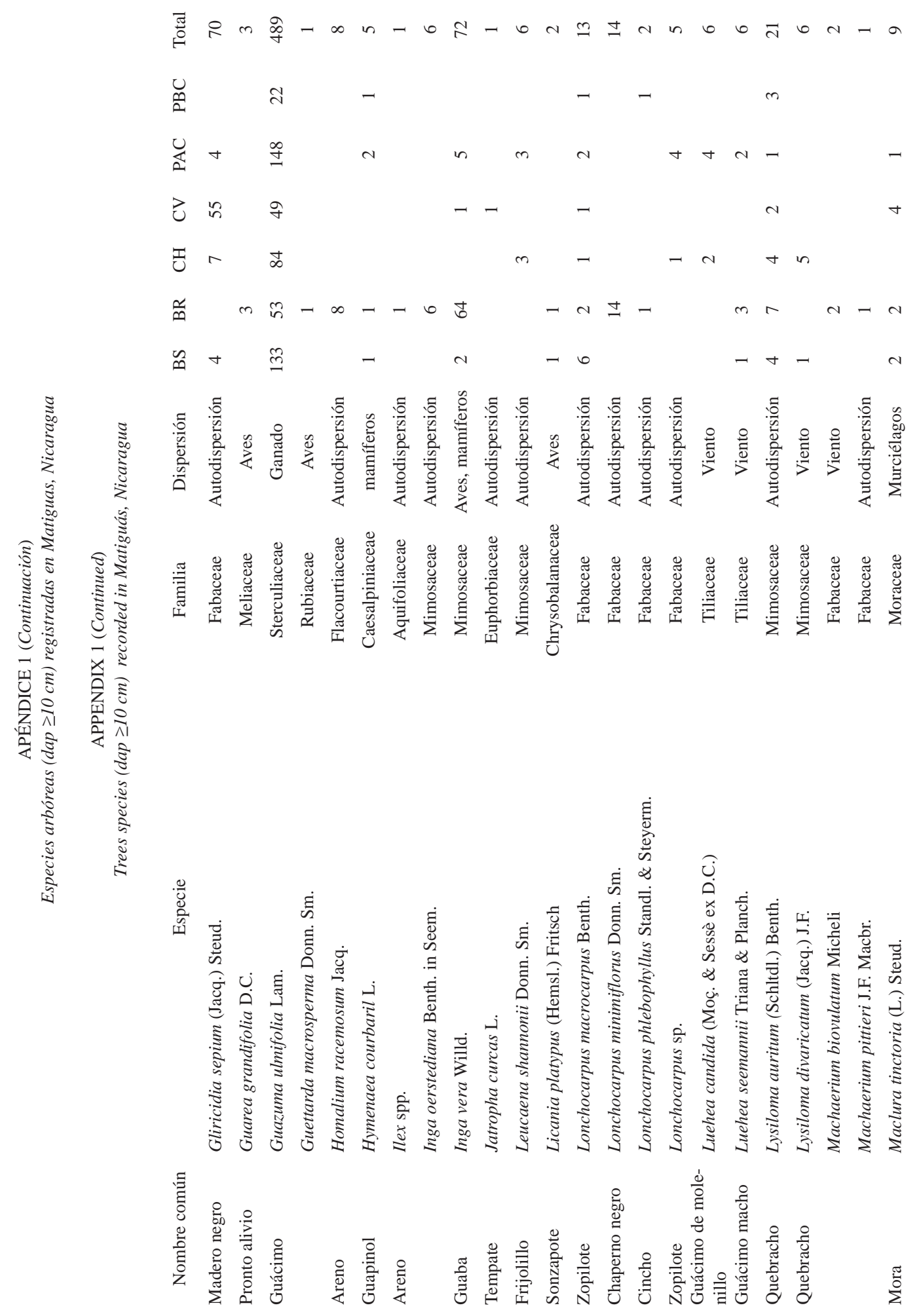

Rev. Biol. Trop. (Int. J. Trop. Biol. ISSN-0034-7744) Vol. 53 (3-4): 387-414, September-December 2005 


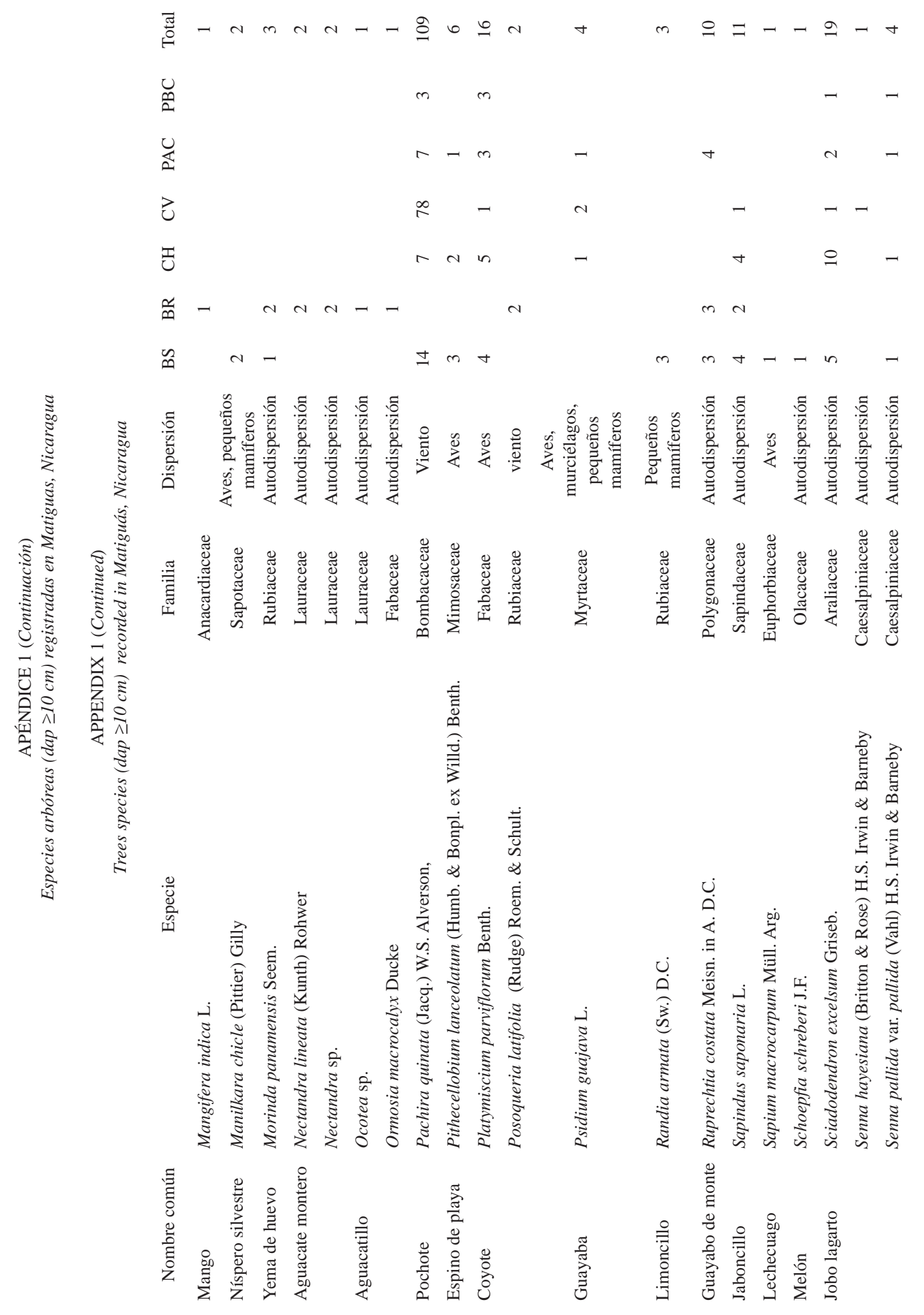




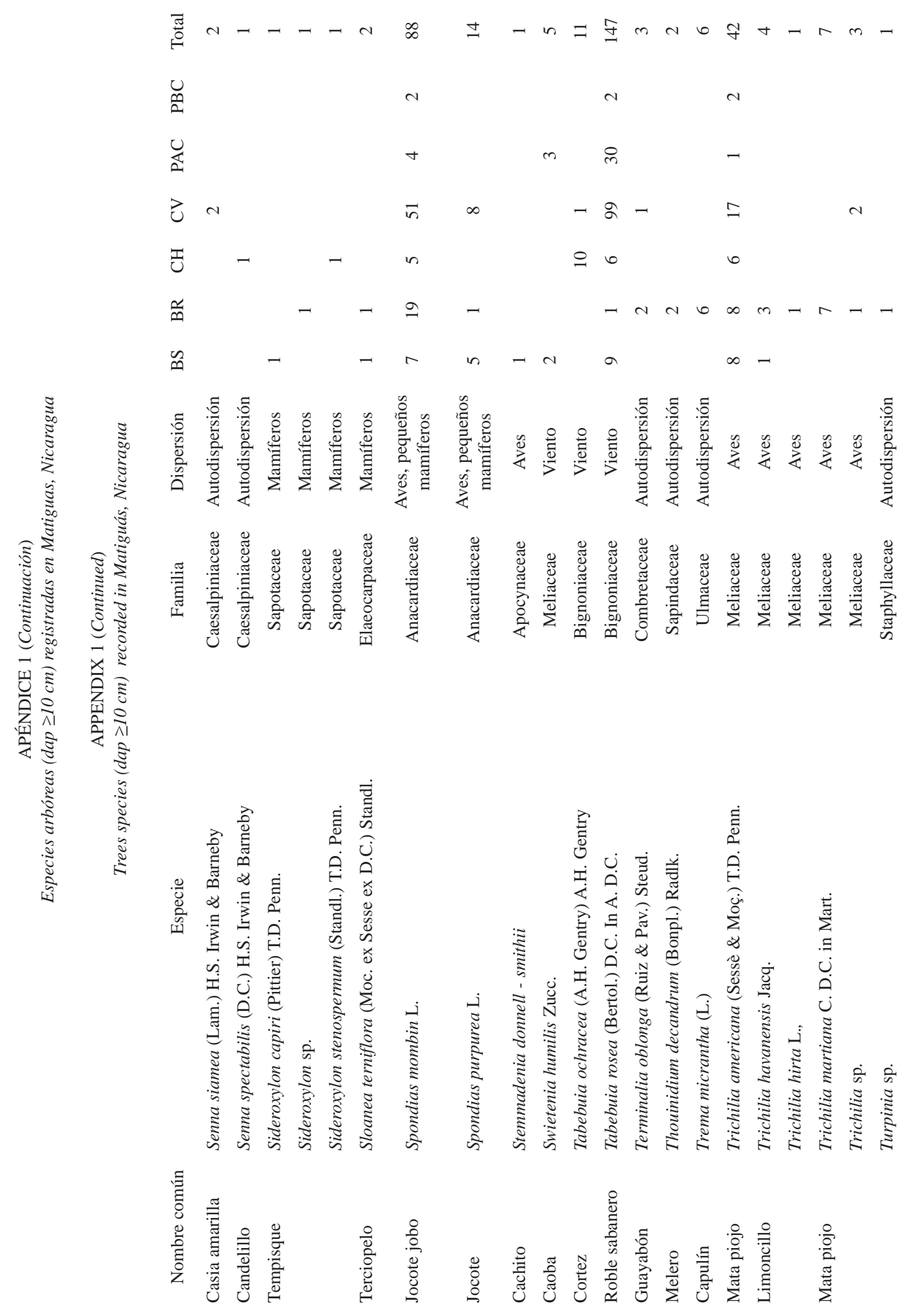

Rev. Biol. Trop. (Int. J. Trop. Biol. ISNN-0034-7744) Vol. 53 (3-4): 387-414, September-December 2005 


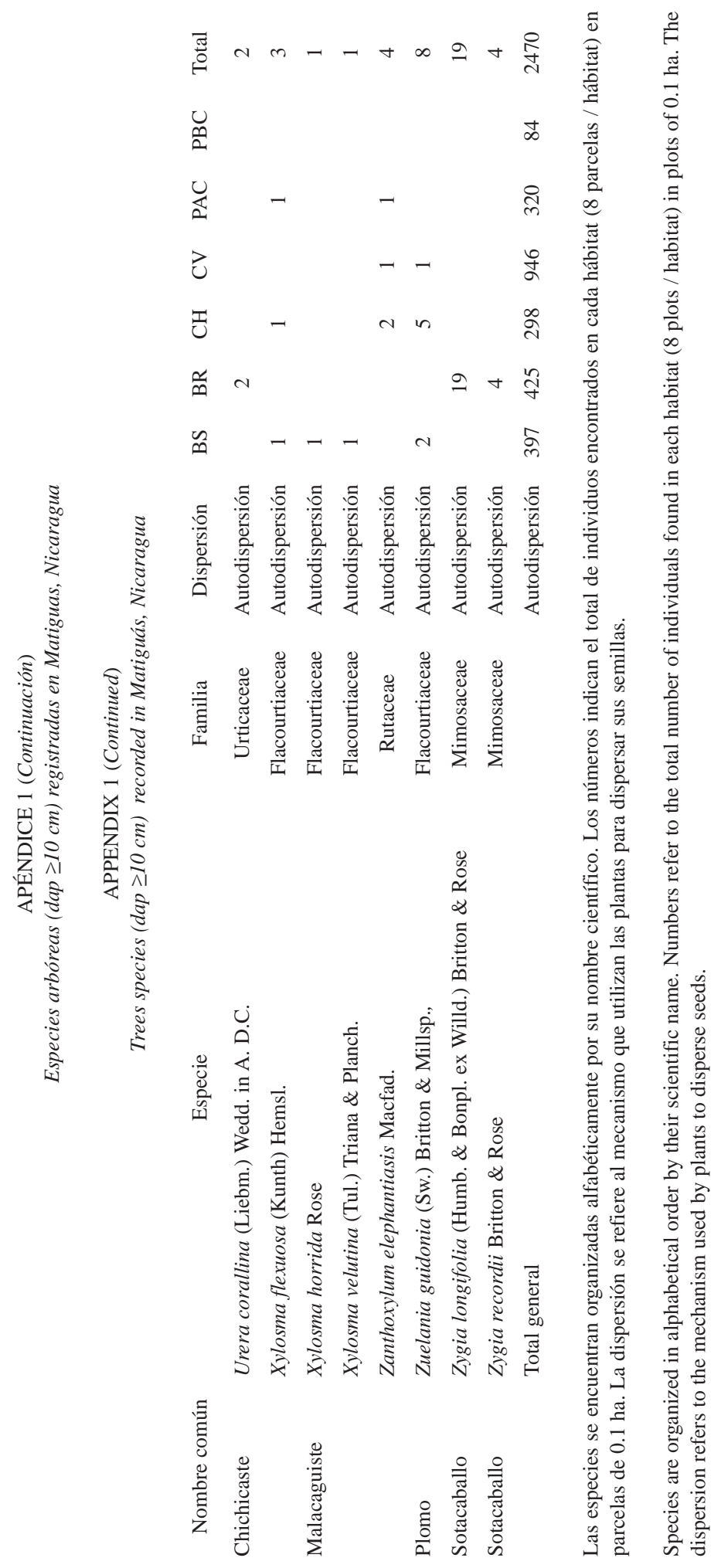




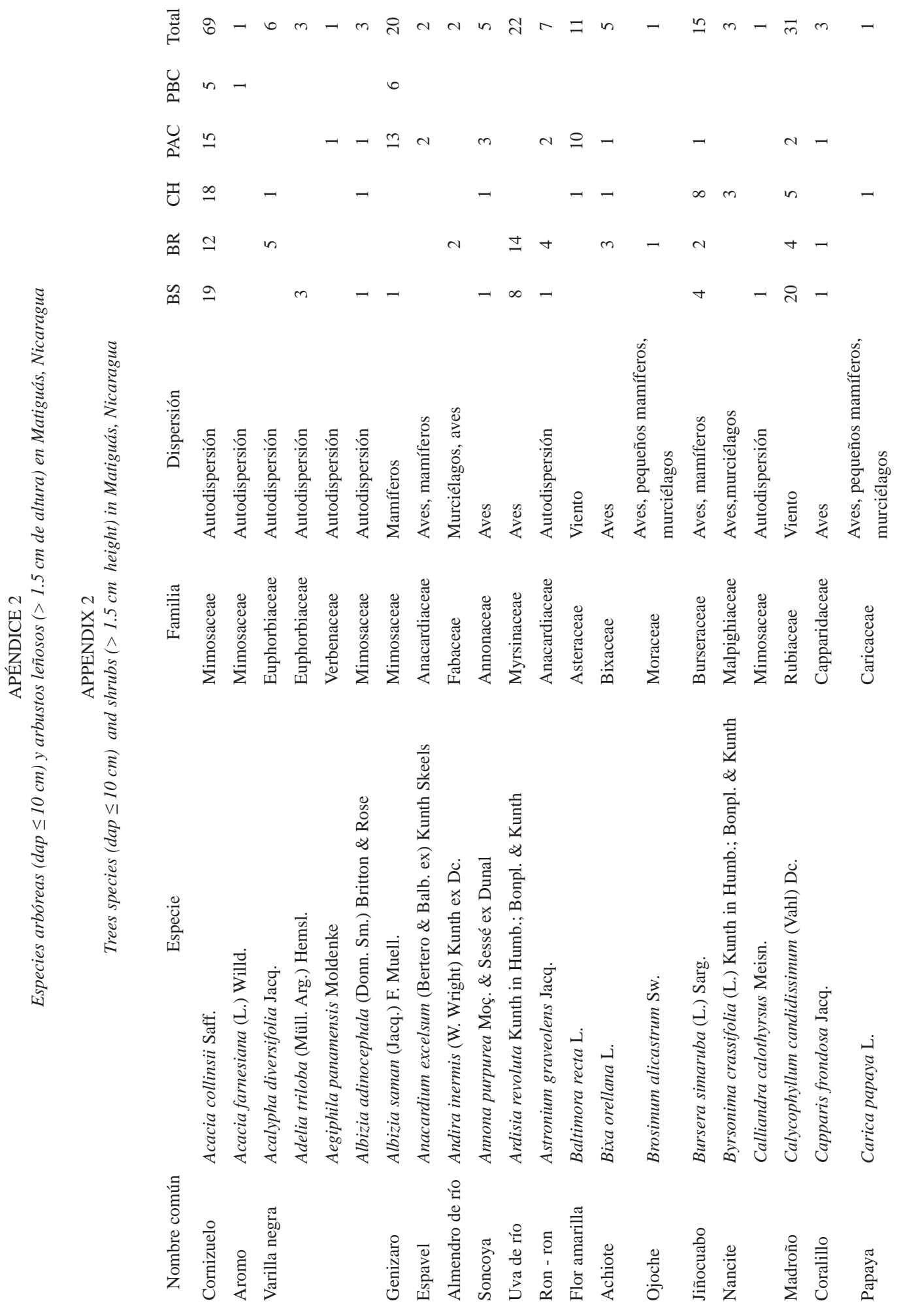

Rev. Biol. Trop. (Int. J. Trop. Biol. ISSN-0034-7744) Vol. 53 (3-4): 387-414, September-December 2005 


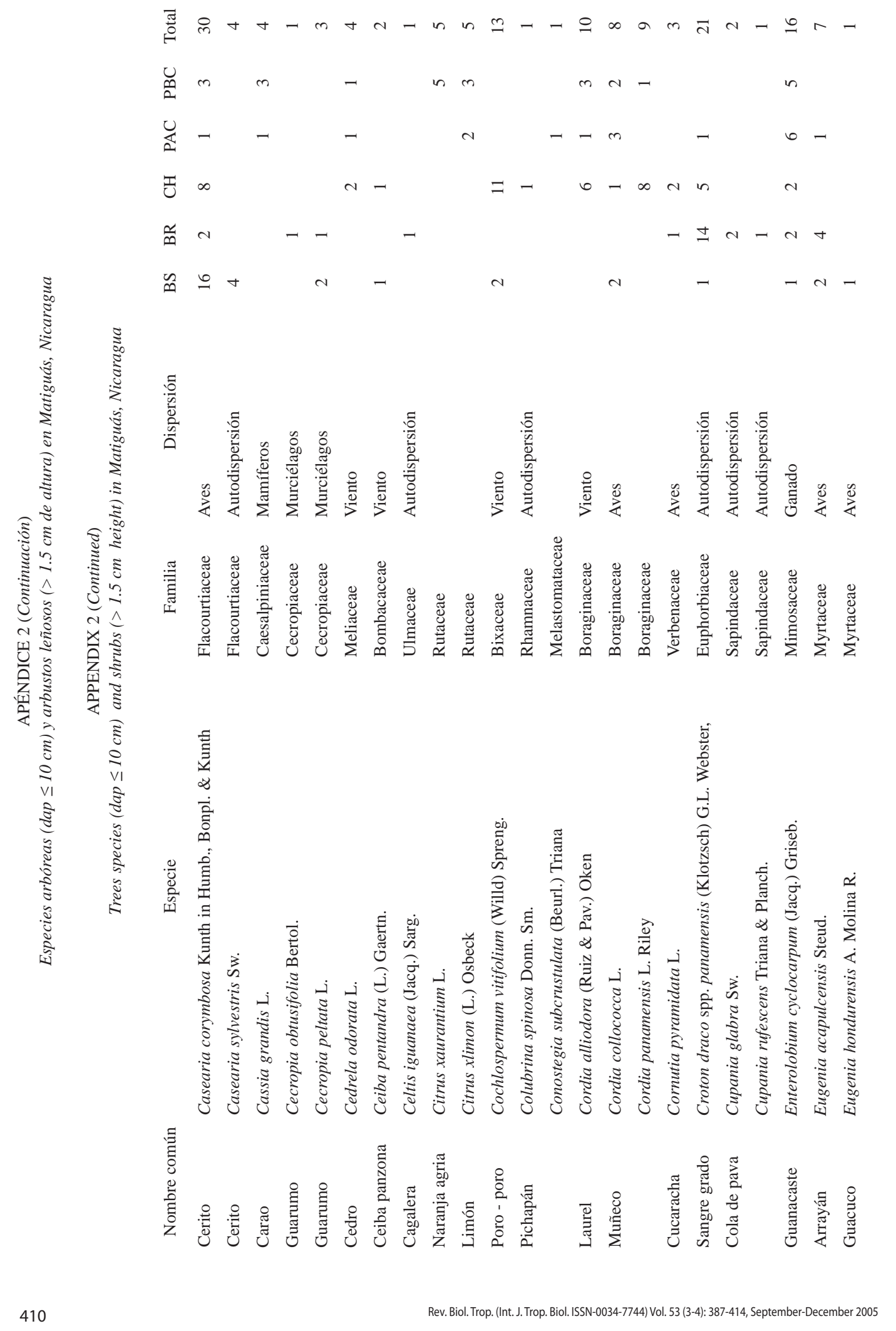




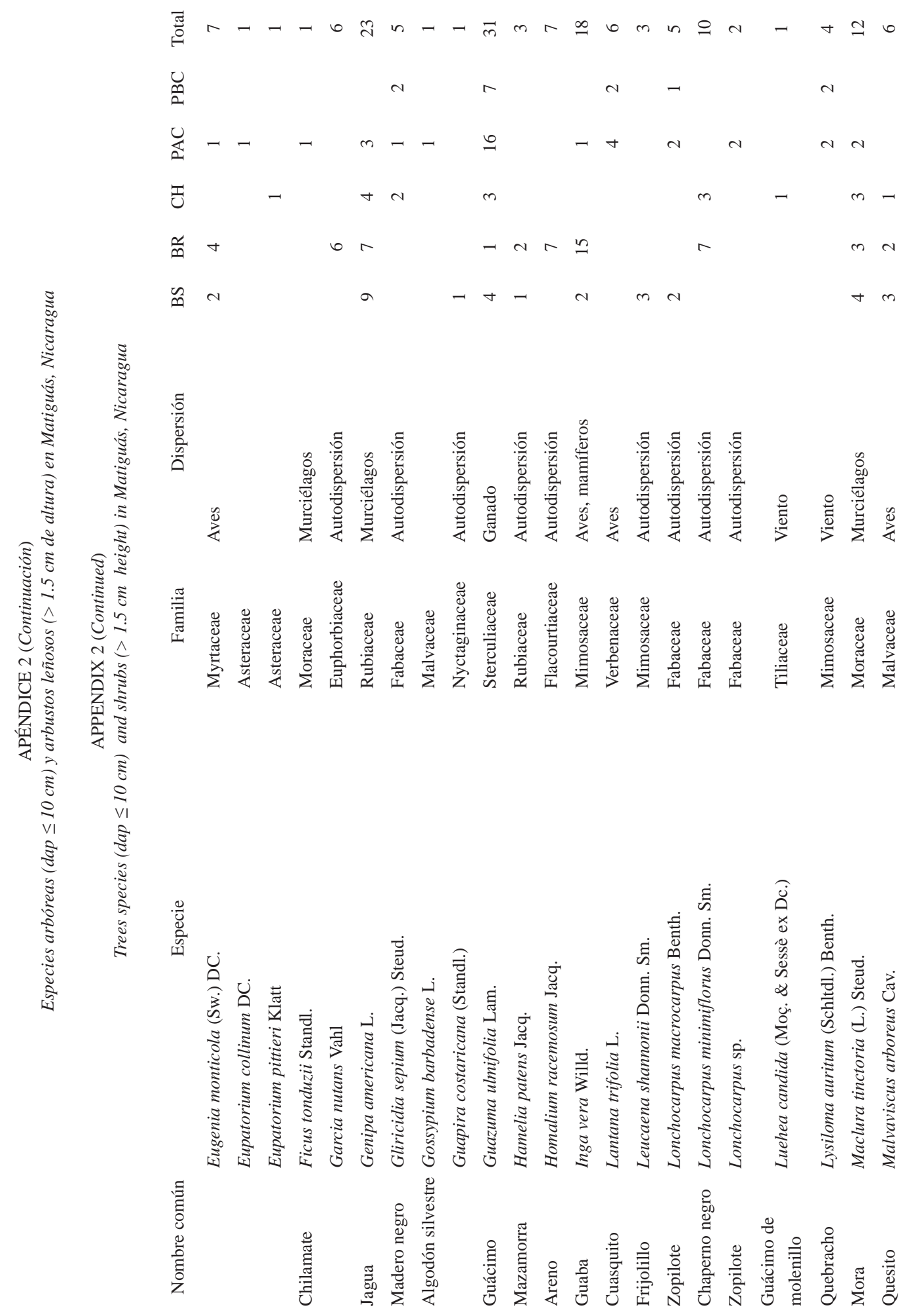

Rev. Biol. Trop. (Int. J. Trop. Biol. ISSN-0034-7744) Vol. 53 (3-4): 387-414, September-December 2005 


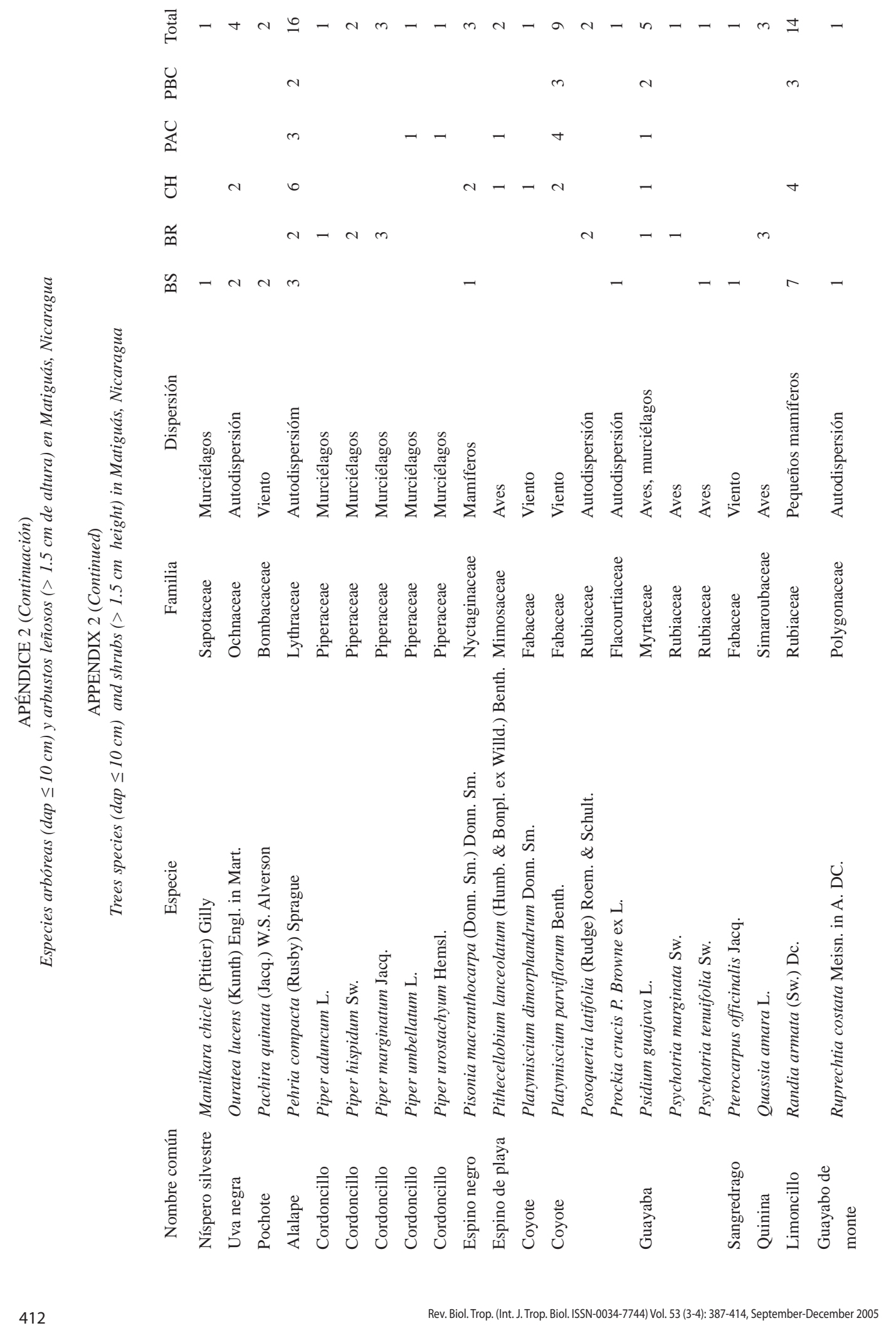




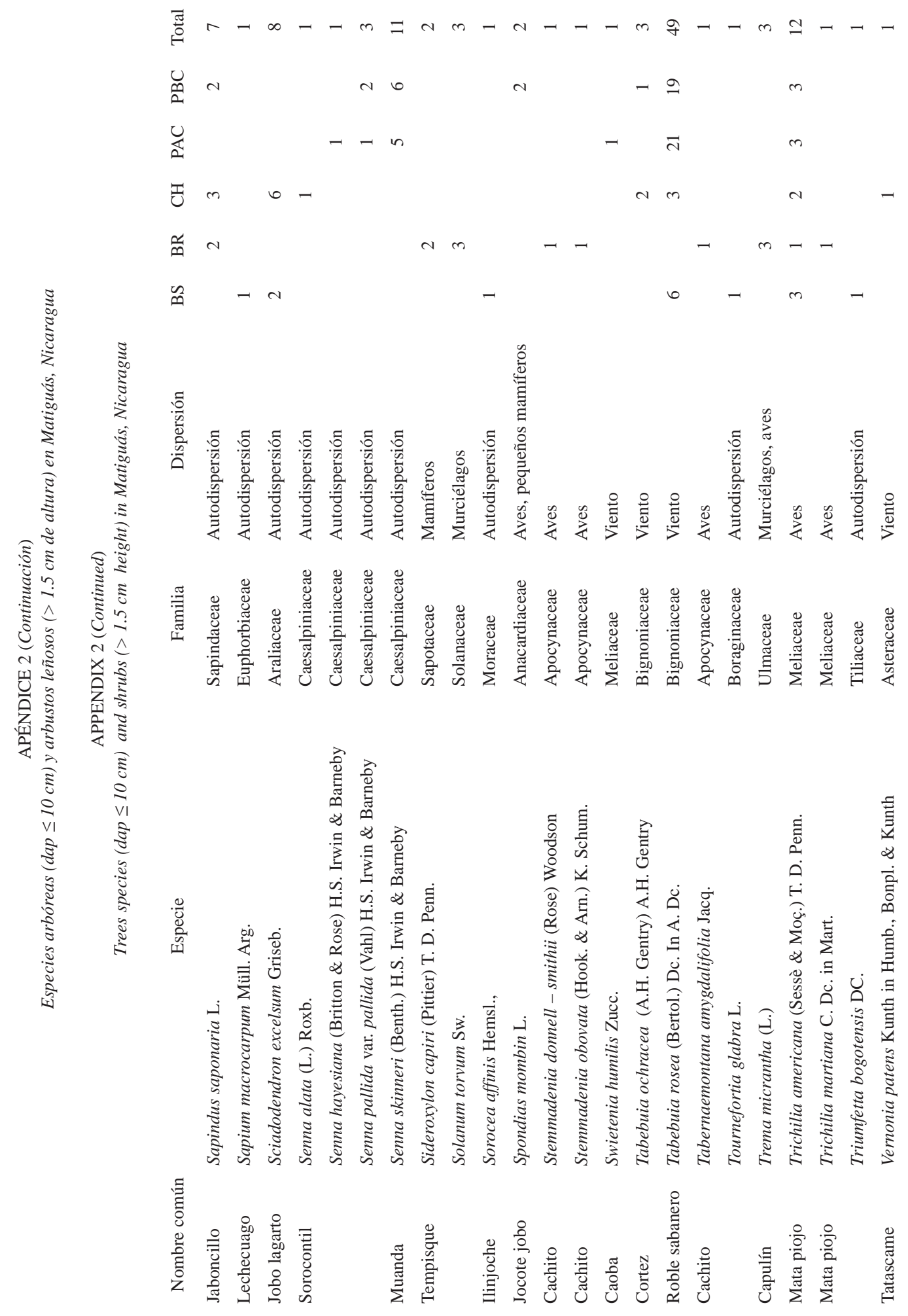

Rev. Biol. Trop. (Int. J. Trop. Biol. ISSN-0034-7744) Vol. 53 (3-4): 387-414, September-December 2005 


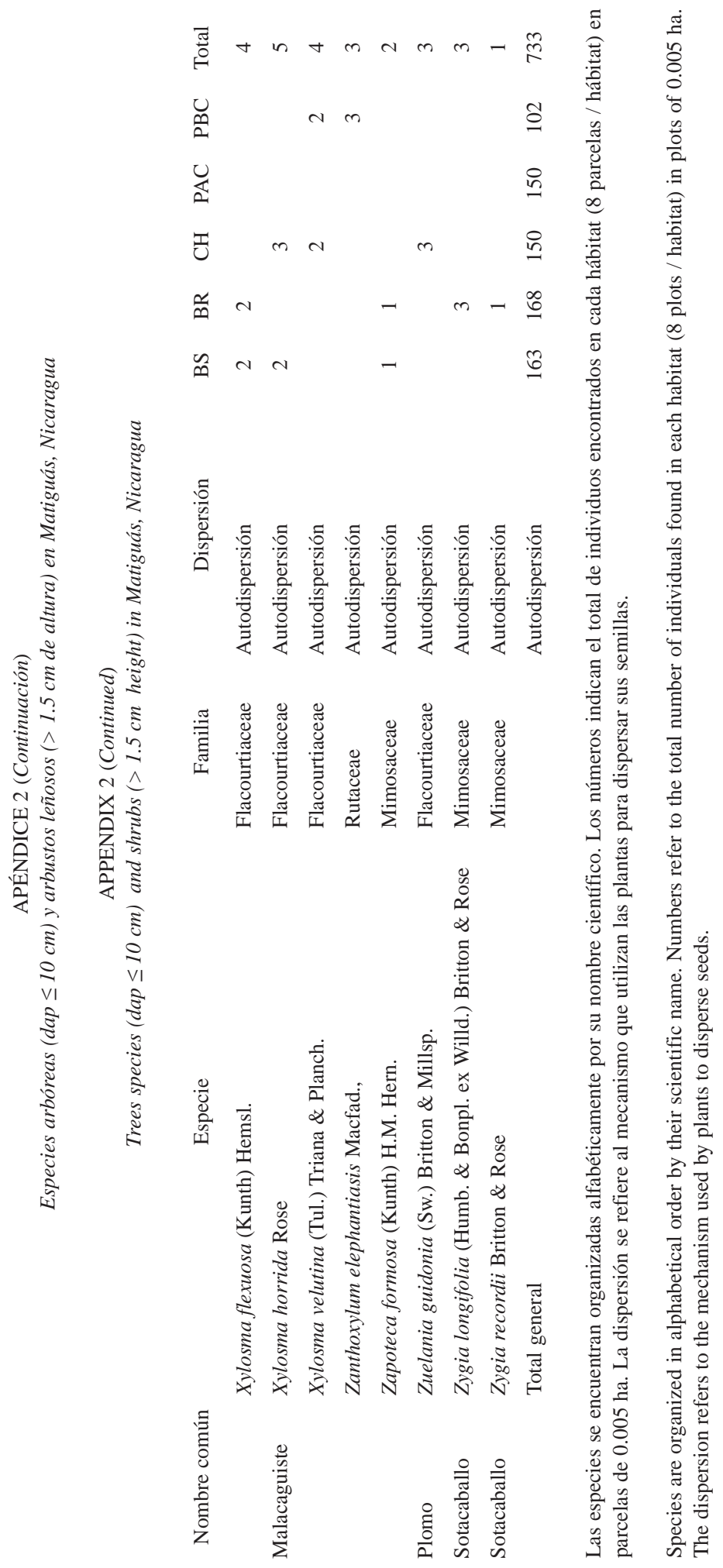

